\title{
Prediction of Pressure Drop in Subsea Pipeline Using Pipesim Software
}

\author{
Jane Ozi \\ Offshore Technology Institute, University of Port Harcourt, Choba, Port Harcourt, Nigeria \\ Tobinson A. Briggs* \\ Mechanical Engineering, University of Port Harcourt, Choba, Port Harcourt, Nigeria \\ Ayoade Kuye \\ Chemical Engineering, University of Port Harcourt, Choba, Port Harcourt, Nigeria
}

\begin{abstract}
The number of offshore developments for which long-distance tie-back is usually implemented has increased recently, leading to increasing pressure loss concerns from such systems. In the literature, it revealed that pressure drop in multi-phase transport is quite complex to compute manually. Hence the need for multi-phase flow simulation software. PIPESIM is a leading industry software currently used in the oil and gas industry for multiphase flow simulation. In this study, a $64 \mathrm{~km}$ subsea pipeline system comprising two sections; $23 \mathrm{~km}, 22.064 \mathrm{in}$ ID and $41 \mathrm{~km}, 24 \mathrm{inch}$ ID, coated with $3 \mathrm{~mm}(0.003 \mathrm{~m})$ polyethene insulation and transporting multiphase hydrocarbon fluid in an ultra-deep-water field was modelled in PIPESIM. Network simulation for the base case was carried out at 114barg (114MPa) inlet pressure and 18.7MMSCfd gas flowrate. The observed system pressure drop was dependent on pipeline inlet pressure, flowrates, and internal pipe diameter. 13.8barg (13.8MPa) was lost from the system for the base case simulation. Sensitivity analysis carried out using Gas volumetric flowrates of 3 , 12 and 18.7 MMSCFd. The inlet pressures of 57, 114 and 171barg combined with six different pipe diameters generated a unique combination of 81 data points that were used in the development of a pressure drop correlation using the LINEST regression analysis tool in Microsoft Excel. At high flowrate and high inlet pressure, the pressure-drop observed was minimal and vice versa. Also, at constant flowrates and inlet pressures, the pressure drop was observed to increase with increasing pipe sizes. An $\mathrm{R}^{2}$ value of 0.9226 was obtained from the analysis. The plot of Predicted Pressure-drop against Calculated pressure-drop similarly gave an $\mathrm{R}^{2}$ value of 0.8025 . Both results showed usefully, and hence the developed correlation can be used as an estimate in the absence of PIPESIM software for pressure drop prediction purposes.
\end{abstract}

Keywords: Pressure drop prediction, Multi-flow Simulation, PIPESIM, Pipe sizing, Regression Analysis

DOI: $10.7176 /$ IEL/10-2-06

Publication date:March $31^{\text {st }} 2020$

\section{Introduction}

The bulk of fluid flow in pipelines/flowlines today, especially in the oil and gas industry is multi-phase in nature (2-phase or 3-phase). When flowing multiphase fluid through pipes, the pressure drop is a critical process parameter which determines the success of the operation. Critical factors affecting pressure drop is the pipe size and flow rate and inlet pressure, which must be carefully chosen to accurately convey the fluid with an acceptable pressure drop to meet operational requirements.

Bai and Bai (2010) stated that ultra-deep-water with water depths ranging from $1500 \mathrm{~m}-3000 \mathrm{~m}$ could be the next march of oil exploration and production. Deep-water oil and gas field development concepts are usually identified in terms of water depth of the offshore location. Since the transition from solely onshore to offshore oil and gas development, there has been a need for making adequate plans before the development of oil and gas fields. A critical challenge for ultra-deep-water subsea field developments is maintaining the system pressure or being able to accurately predict the system pressure loss to avoid back pressures or slug flow. This condition has attracted a huge share of the oil and gas industries total annual cost budgets, reserves portfolio and production output. These plans are usually considered during the field development planning of offshore oil and gas fields. Several factors are considered in the field development plan (FDP), but of utmost importance is considering the viability of flow in the field (Flow Assurance).

In more recent times, the growth potentials and pace of development of deep-water projects have been impeded by a growing trend of the high cost of field development, given the current trend of international oil price. But the economics of oil and gas projects correlates strongly with the cost of field production facilities, therefore minimizing facilities cost through efficient sizing of equipment would help improve the current economic outlook of deep-water projects. Understanding the system flow dynamics and the pressure drop due to the terrain is always a first step towards ensuring efficient sizing.

The network of subsea flow-lines forms a huge part of subsea development. In any subsea development, 
production fluid must pass through jumpers, manifolds and risers, which are already designed to take into consideration flow assurance challenges, pressure drop inclusive. However, when tieback distances are longer by several meters, new flow assurance challenges emerge, some of which are cost and excessive pressure drop. The main goal of concept design is to identify, assess and define a development option that safely satisfies expected production flow profile at a minimum feasible cost. This process involves technical consideration and analysis of several design and cost factors such as water depth location, specifications of equipment capacity, manufacturability, constructability, and cost. During conceptual design, there is a lack of design data to specify equipment sizes and other parameters fully. Consequently, it is common practice to assume or adopt a "conservative case" approach during development studies, to avoid underestimating actual requirements early in design. The solution to the problem is usually achieved with the aid of multiphase simulators that take minimal data and produce results of system behaviour.

With deep-water operations, it becomes imperative that we can predict pressure losses over field operations, to manage flow assurance issues, including slug flow and liquid hold-up. Therefore, an accurate and reliable method of estimating pressure loss in a system is needed. This present study model, a pipeline system, transporting Multiphase hydrocarbon fluid in the ultra-deep-water subsea production field using PIPESIM. Parametric studies would also be performed with PIPESIM using different flowline sizes and different flow rates to ascertain their effects on pressure loss and to select the line size and flow rate that best meet the system outlet pressure requirement

Selecting the optimum pipe size entails selecting the pipe size that mitigates flow assurance issues such as slug, undesired pressure-drop amongst others. In order to achieve flow stability, the pressure drop along the system profile must be known. PIPESIM is a powerful tool for achieving such. Multi-phase flow is undesirable in most applications. However, the flow of the two or three phases cannot be eliminated even with the use of subsea processing. One of the adverse effects of multiphase flow is the unsteady state associated with it frequently result in excessive pressure drops in the flow system. This situation is a severe problem in the industry which needs due consideration.

This study aims to simulate a typical Subsea pipeline in PIPESIM to predict the Pressure-drop in the system along with the pipeline profile.

Specific objectives of the study include:

i. Review previous works on multiphase simulation to establish a knowledge gap and establish a mathematical basis of software.

ii. Describe a typical subsea pipeline and its design inputs

iii. Simulate a typical subsea pipeline using PIPESIM software and determine pressure drop along flow-path

iv. $\quad$ Perform Sensitivity analysis using some process parameters

v. Perform regression analysis using excel software to establish a correlation for pressure drop

Generally, the offtake of petroleum products via pipeline poses significant threats, mainly, flow assurance issues such as slug flow, liquid hold-up, due to pressure loss. This situation presents a challenge to the flow because of the reduced inner diameter or blocked pipelines in severe cases (Sloan et al., 2014). The production interruption because of blocked flowlines can cause very significant financial losses. Therefore, to keep these adverse effects at its minimal, pipeline design via sensitivity analysis for flow assurance must be considered. Ability to select optimum pipeline size and flow rate (a typical flow assurance issue) is important in the safe and reliable delivery of process fluid to the top side equipment.

This study serves as a reference document to students, researchers and flow assurance engineers in providing ideas on the implications of design input parameters (pipeline diameters, flow rates, etc.) and other operating conditions required in the design and optimization of subsea oil \& gas transportation pipelines on pressure drop and flow assurance in general.

In the course of this study, the following areas/scope of work shall cover:

i. Modelling of a pipeline system transporting multiphase hydrocarbon fluid in deep-water subsea production field using PIPESIM.

ii. Sensitivity studies using PIPESIM to investigate the relationship and effects of pipeline sizes, inlet pressure and flow rates on pressure drop.

iii. Regression analysis using excel software to establish a correlation for pressure drop

\section{The mathematical basis of PIPESIM software}

This section discusses the methodology used in achieving the aim and objectives of this study. The mathematical basis of PIPESIM software is discussed. The Input data and pipeline description are also discussed. The methodology used in this present study is computer simulation. Pressure drop correlation was developed with existing data using the LINEST statistical function in Microsoft Excel.

The PIPESIM software is a steady-state multiphase simulator used extensively in the simulation of Pipe Networks and Wells. PIPESIM utilizes different correlations found in the literature for simulation of horizontal or vertical flows. PIPESIM, like other multiphase flow software, is capable of predicting the pressure variations along 
the length of fluid travel and also predict the flow regimes for horizontal and vertical flow. PIPESIM categorizes multiphase vertical flow into four different flow regimes, bubble flow, slug flow, slug-mist transition (churn flow) and mist flow. Horizontal Multiphase flow, on the other hand, is categorized into the stratified flow (smooth and wavy), Intermittent (slug and plug) and Distributed (bubble and mist).

Some of the Correlation used in PIPESIM for the calculation of pressure losses in vertical and horizontal losses are;

1. Horizontal (Barker Jardine, Beggs and Brill Original, Beggs and Brill Revised, Dukler, (AGA) and Flanigan, Dukler, (AGA) and Flanigan (Eaton Hold-up), Eaton-Oliemans, Hughmark-Dukler, LEDA PM, Minami and Brill, Mukherjee and Brill, No-Slip Correlation, OLGAS 2-Phase/ OLGAS 2000 3-Phase, Oliemans, TUFFP unified Mechanistic Model, Xiao, Xiao (modified film). (PIPESIM 2017, User Manual)

2. Vertical (Ansari, Aziz, Govier and Forgasi, Beggs and Brill Original, Beggs and Brill Revised, Duns and Ros, Gomez, Gomez enhanced, Govier and Aziz, Gray, Gray Modified, Gregory, Hagedorn and Brown, Mukherjee and Brill, NO SLIP Correlation, OLGAS 2-Phase/ OLGAS 3-Phase, LEDA 2-Phase/3-Phase, Orkiszewski, TUFFP unified Mechanistic Model). (PIPESIM 2017, User Manual)

Beggs and Brill (1973) gave the correlation for estimating pressure drop in multiphase flow system as given by equation (1).

$-\frac{d P}{d z}=-\frac{d P}{d z}=\frac{\frac{g}{g_{C}} \sin \theta\left[\rho_{L} H_{L}+\rho_{g}\left(1-H_{L}\right)\right]+\frac{f_{T P} G_{m} V_{m}}{2 g_{C} d}}{1-\frac{\left[\rho_{L} H_{L}+\rho_{g}\left(1-H_{L}\right)\right] V_{m} V_{S L}}{g_{C} P}}$

Where pressure gradient, $g=$ acceleration due to gravity, $\rho_{L}=$ liquid density, $H_{L}=$ liquid hold-up fraction, $G_{m}=$ mixture mass flow rate $=G_{g}+G_{L}, \theta=$ angle of inclination, $g=$ acceleration due to gravity, $g_{c}=$ gravitational constant, $V_{m}=$ mixture velocity $=\left(q_{L}+q_{g}\right) / A_{p}, q_{L}=$ liquid volumetric flowrate, $q_{g}=$ gas volumetric flow rate, $A_{p}=$ pipe Area, $V_{s L}=$ superficial liquid velocity $=q_{L} / A_{p}, f_{T P}=$ two-phase friction factor and $P=$ pressure.

\subsection{Input Data and Pipeline description}

To run the simulation in PIPESIM, specific input data are required. Data from Mansoori et al., 2014 was used in this study. Two different pipe sizes were used, the first running for a distance of $23 \mathrm{~km}$ (24 in OD) and the remaining $41 \mathrm{~km}$ using a different pipe size (26 in OD). A digitizer software was used to extract data from an existing plot in a graphical report. The thermal conductivity of polyethene the coating material was sourced from an engineering data book.

Also required for the simulation was a definition of fluid flowing in the system. PIPESIM has several methods available for the definition of fluid in the system. The compositional fluid and the details of moles per cent, density and molecular weight for fluid components.

\subsection{PIPESIM Simulation}

This section describes the simulation procedure using PIPESIM. Figure1 shows the simulation flow chart. 


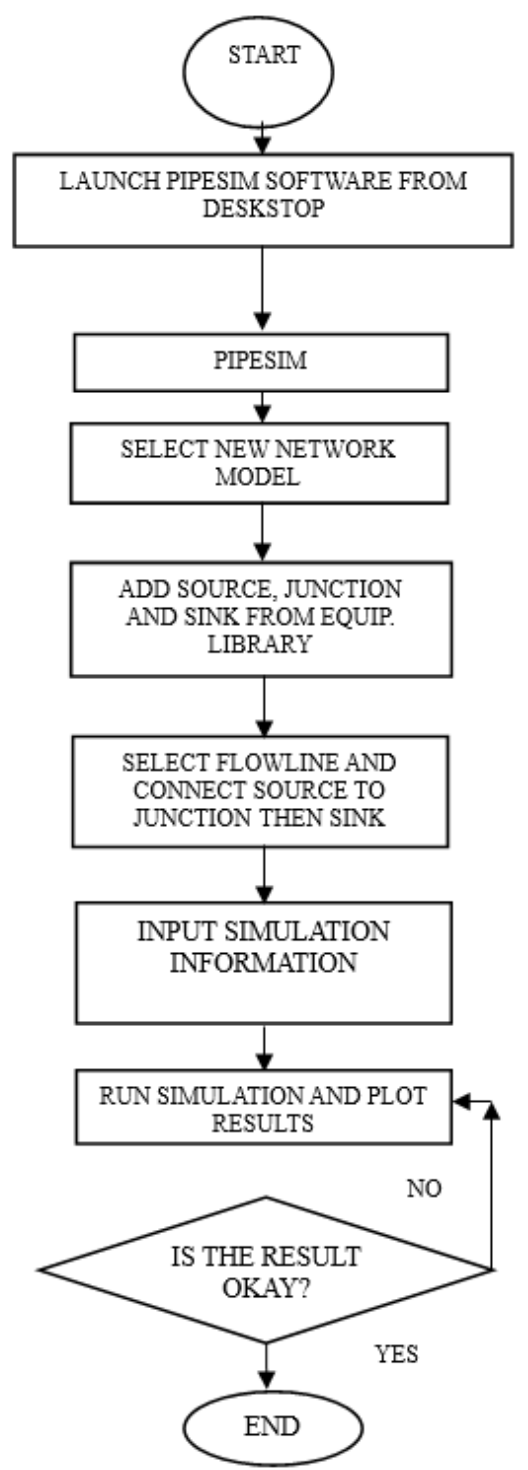

Figure 1 Simulation flowchart for PIPESIM

2.2.1 Simulation Procedure on PIPESIM

1. Launch PIPESIM software from the desktop and select network module

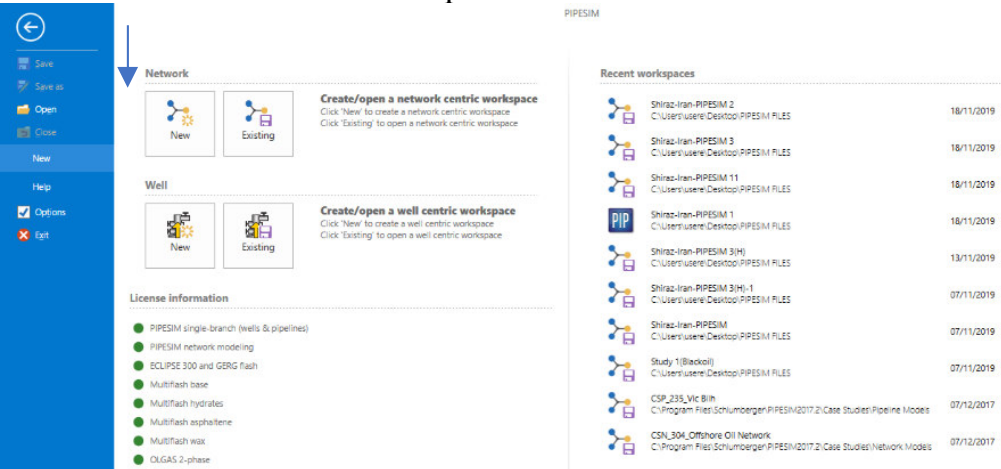

Figure 2 Launching PIPESIM Software 
2. Add source, sink and Junction from the equipment library.

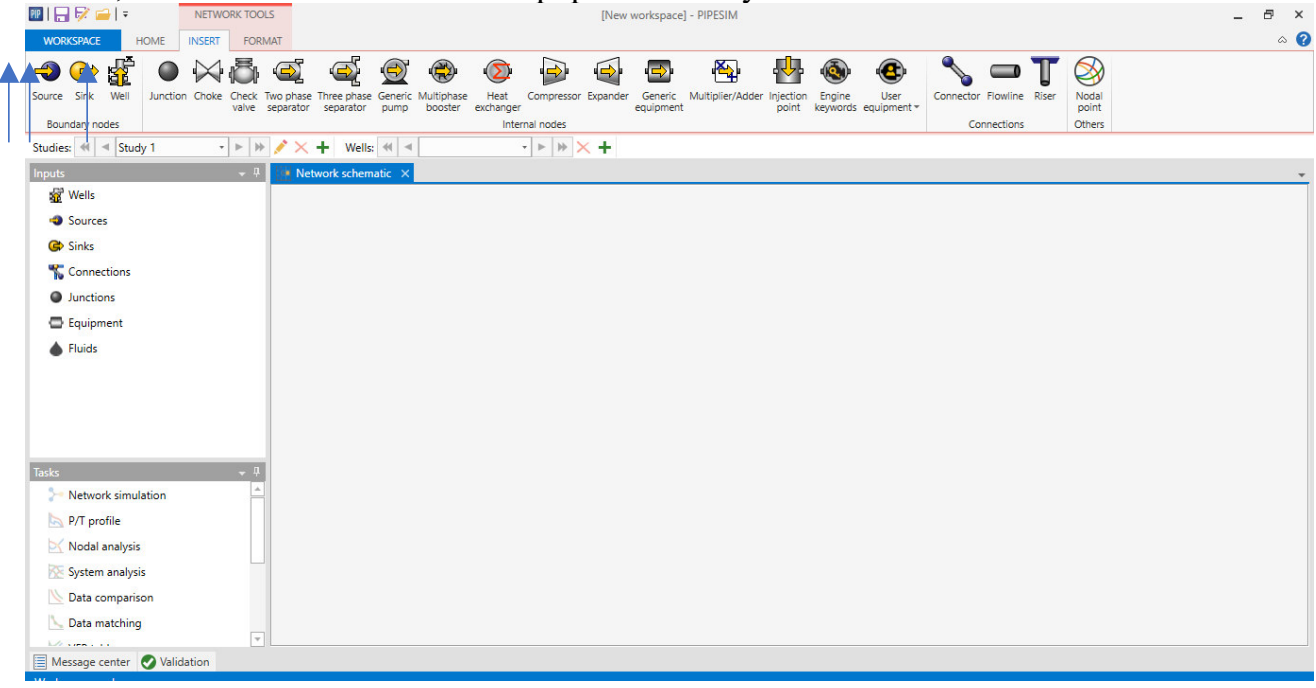

Figure 3 Adding Source, Sink and Junction in PIPESIM

3. Select flowline and connect the source to the junction

4. Select flowline again and connect from junction then to sink.

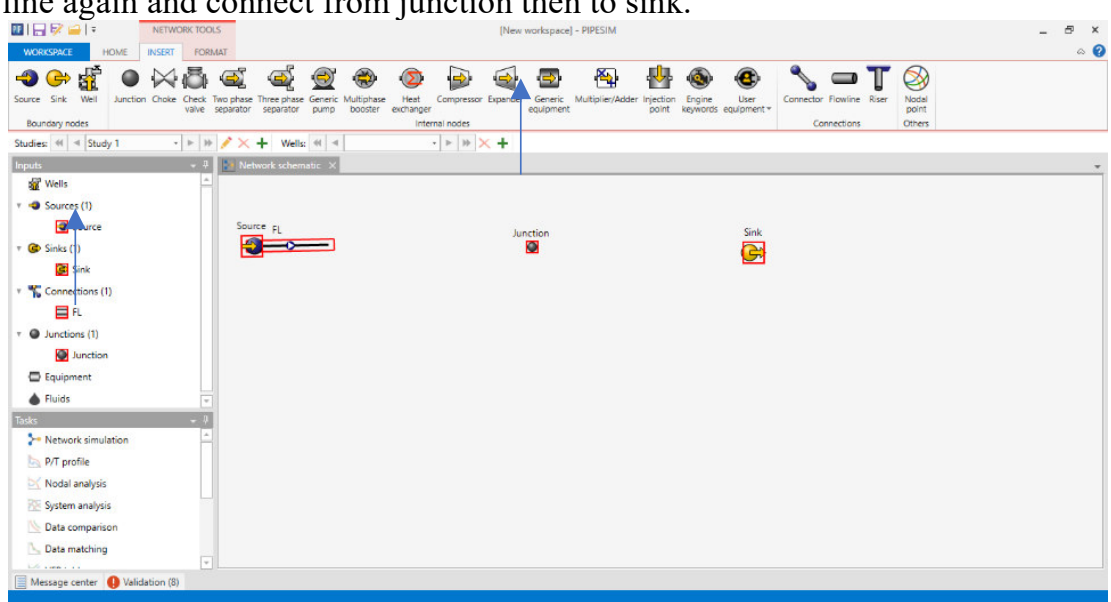

Figure 4 Connecting Flowline in PIPESIM

5. From the Menu Bar, click on Fluid Manager and select compositional. Build the compositional fluid. Set PVT package to Multi-flash, equation of state to 3-parameter Peng-Robinson, viscosity to Pedersen, volume shift correlation to Multi-flash, critical property correlation to Kesler-Lee, thermal coefficient correlation to Multi-flash, Acf. Correlation to Kesler-Lee and Salinity model to none. Select pure components from the component library to add them to the current list. Add pseudo-components by clicking on the new button and enter at least two properties to define all other properties.

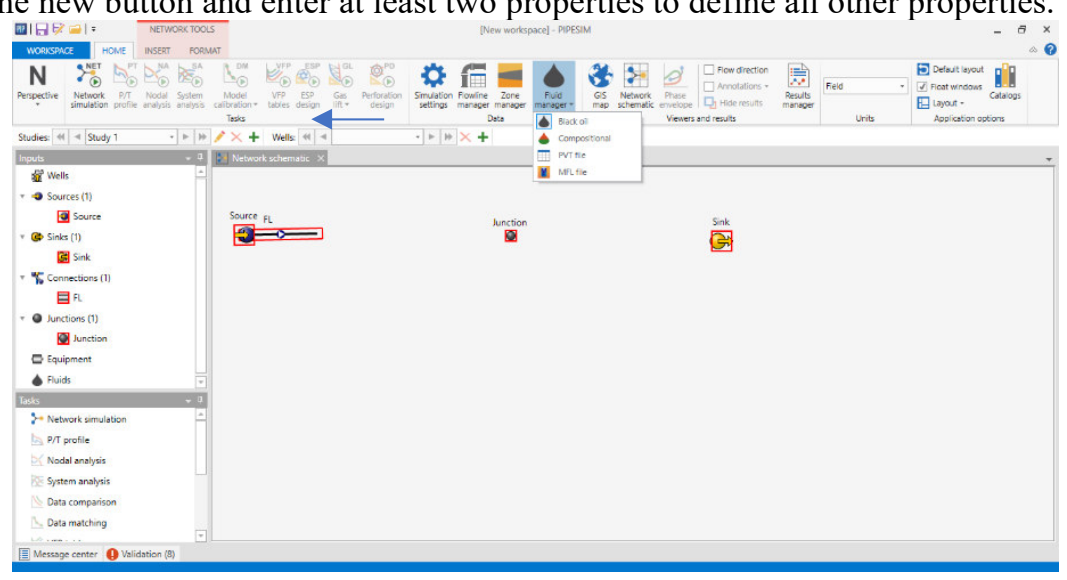

Figure 5a Building Fluid Composition in PIPESIM 


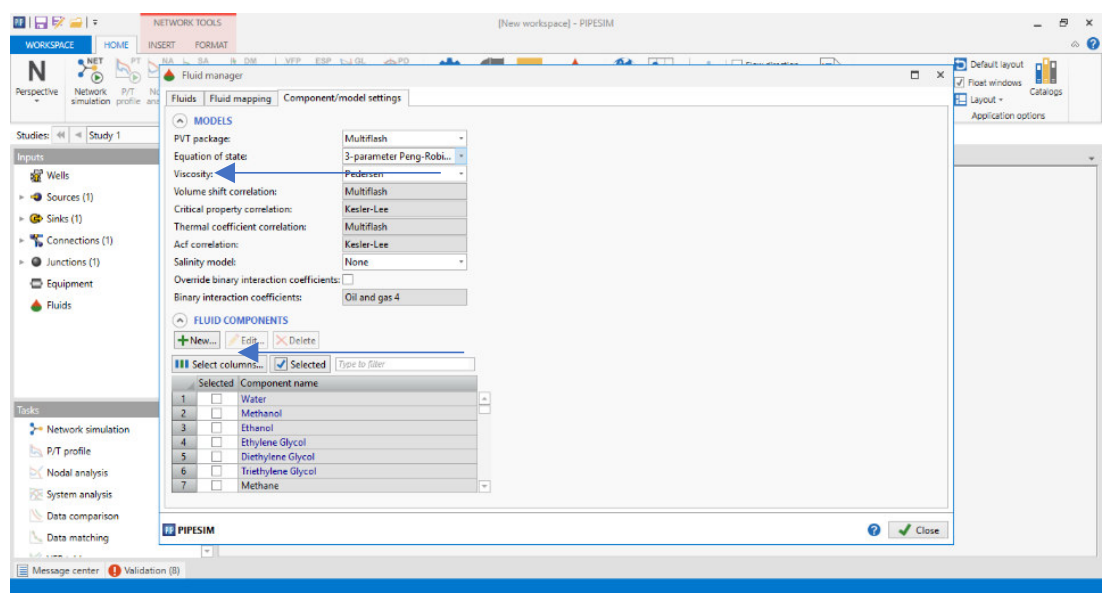

Figure 5b Adding Pure Components in PIPESIM

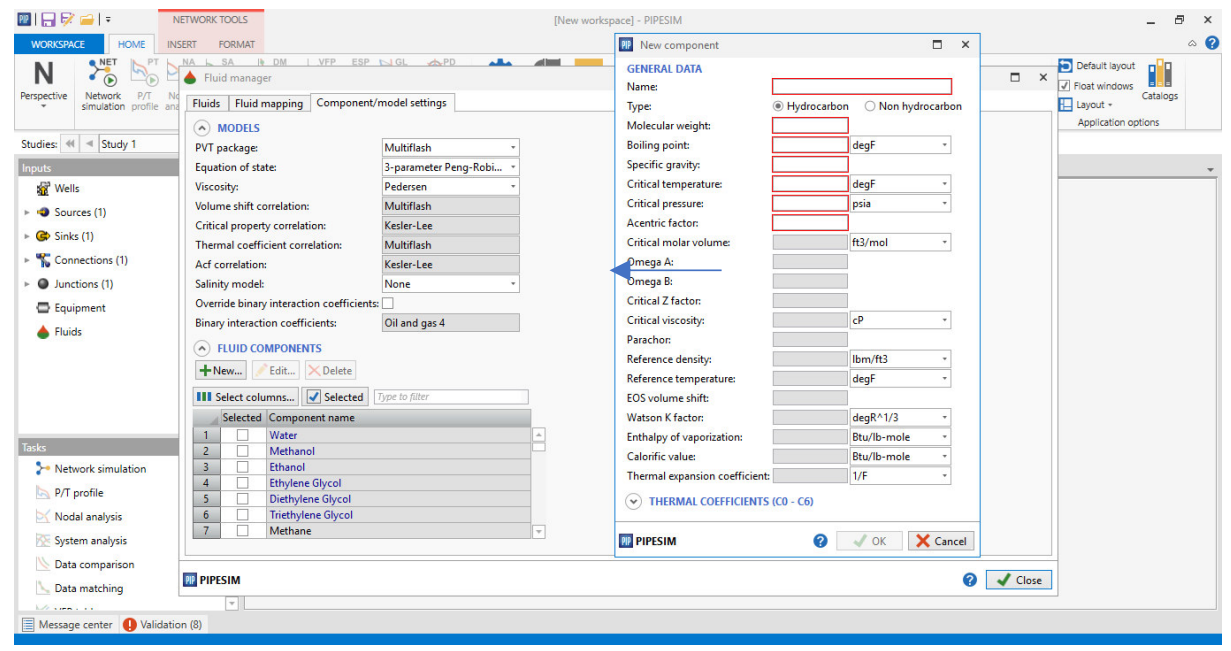

Figure 5c Defining Pseudo-components in PIPESIM

6. Open the flowlines, rename flowlines and select the detailed and subsea buttons. Enter Profile data. To ensure continuity after the second pipe segment was built as a continuation from the previous section. The internal pipe diameter was chosen based on outer pipe diameter (24 and 26-inches) ensuring there is approximately 1 -inch wall thickness.

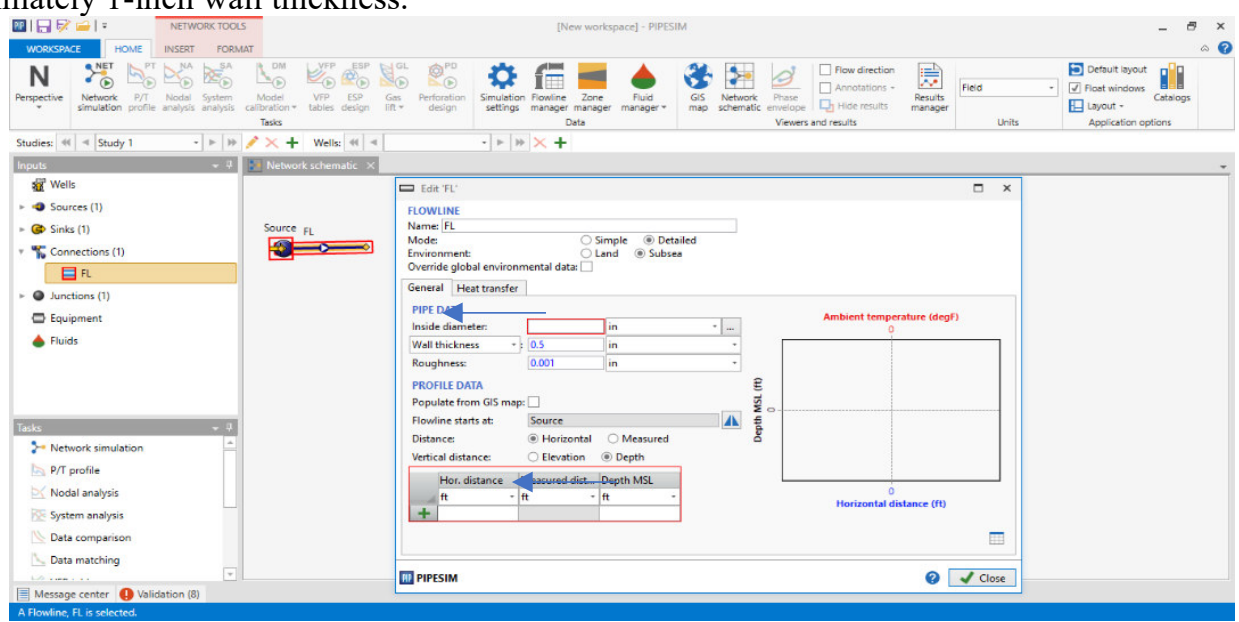

Figure 6 Specifying Flowline details in PIPESIM 
7. Input the heat transfer data at this stage. Use the calculate option for the heat transfer data

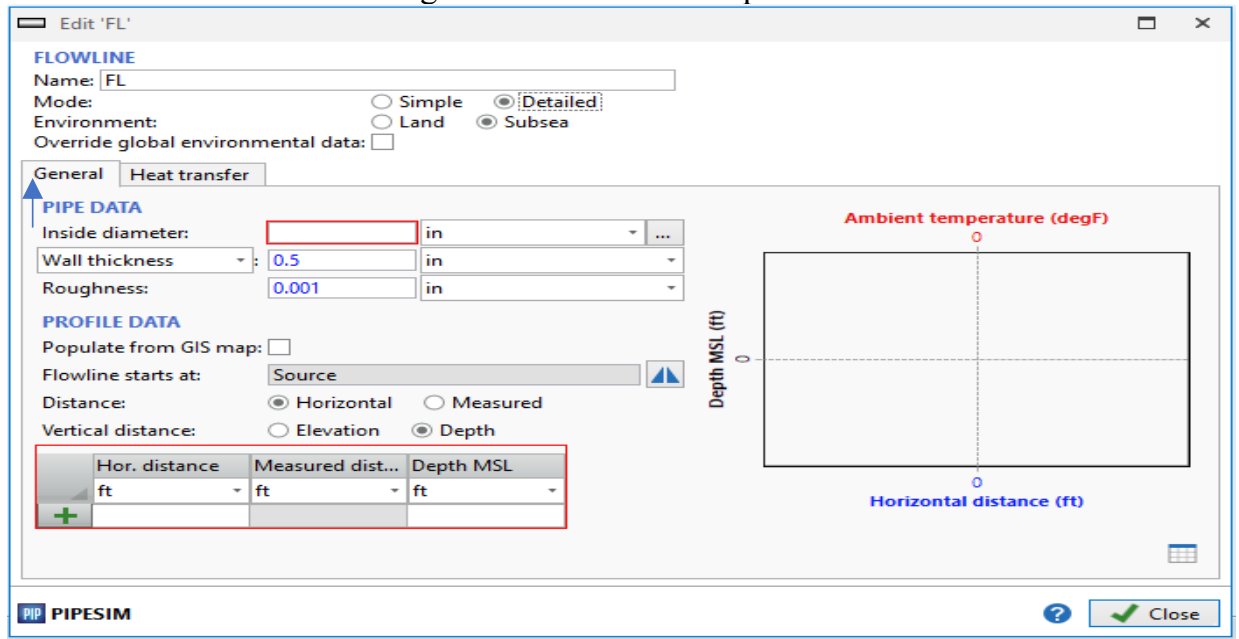

Figure 7a Adding Heat transfer data in PIPESIM

\section{Edit ' $F L$ '}

FLOWLINE

Name: FL

Mode:

Environment:

Override global environmental data:

General Heat transfer

THERMAL DATA

$U$ Value input:

$U$ Value type:

Heat transfer coefficient:

Inside film coefficient:

Specify $\bigcirc$ Calculate
\begin{tabular}{|l|l|}
\hline Insulated & \\
\hline 0.2 & Btu/(h.degF.ft2) \\
\hline & Include $\bigcirc$ Calculate separately \\
\hline
\end{tabular}

Figure $7 \mathrm{~b}$ Specifying Heat transfer data 


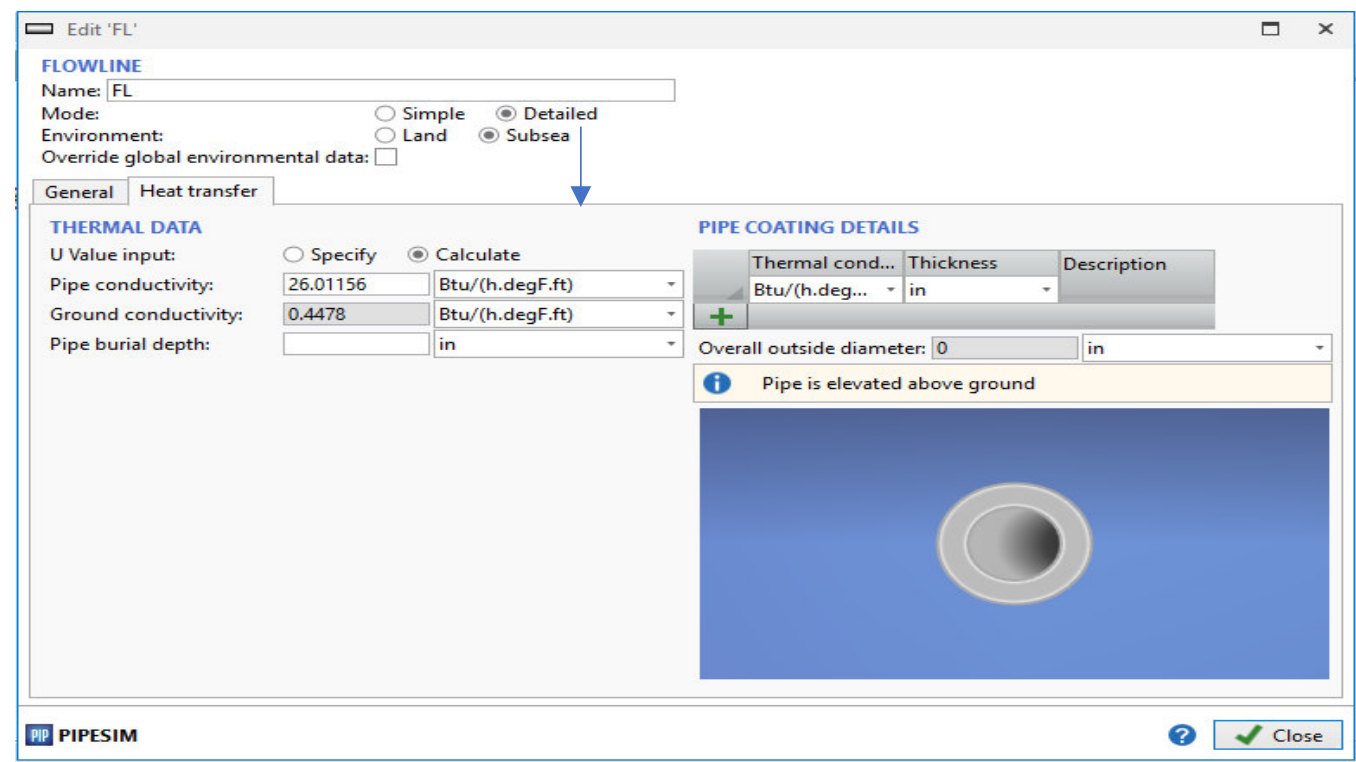

Figure 7c Specifying Flowline Coating details in PIPESIM

8. Open source and supply the fluid conditions (temperature, pressure and gas flowrate)

\begin{tabular}{|c|c|c|c|}
\hline$\rightarrow$ Edit 'Source' & & & $\square \times$ \\
\hline \multicolumn{4}{|l|}{ SOURCE } \\
\hline Name: & \multicolumn{2}{|l|}{ Source } & \\
\hline Active: & \multicolumn{2}{|l|}{$\square$} & \\
\hline \multicolumn{4}{|c|}{ FLUID MODEL } \\
\hline \multicolumn{3}{|c|}{ No global fluids available. } & + New... \\
\hline \multicolumn{4}{|c|}{ ( ) PRESSURE/FLOWRATE BOUNDARY CONDITIONS } \\
\hline PQ curve: & $\square$ & & \\
\hline Pressure: & & psia & \\
\hline Temperature: & 世 & $\operatorname{deg} F$ & \\
\hline Liquid flowrate *: & & STB $/ \mathrm{d}$ & \\
\hline PIP PIPESIM & & $?$ & $\checkmark$ Close \\
\hline
\end{tabular}

Figure 8 Specifying Initial Fluid Conditions in PIPESIM

9. Simulate the junction as a source to clear all validation centre error message. The complete network model look is shown in Figure10.

10. On the menu bar, click on network simulation and supply the initial conditions. 


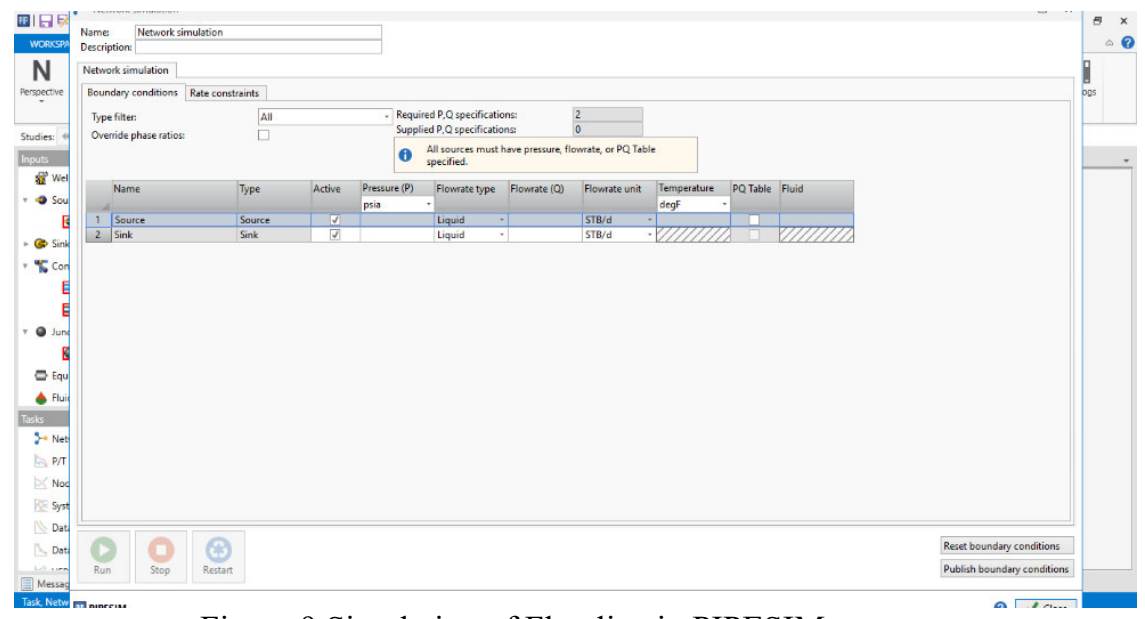

Figure 9 Simulation of Flowline in PIPESIM

11. Run Simulation for typical engine console output in PIPESIM. The grid result for a profile result (pressure against horizontal distance) will be obtained.

12. If results are satisfactory, proceed to result from manager to view and export result in either tabular or graphical format.

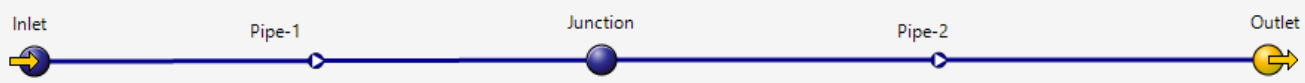

Figure 10 Pictorial Representation of PIPESIM Model

\subsection{Pressure drop Correlation Model}

The Pressure drop was analysed while varying four process parameters pipe internal diameter (d1 and d2) for sections one and two, respectively, gas volumetric flowrates (q) and inlet pressure (P). Table 1 shows the generated data point from PIPESIM for three flowrates (3MMSCf/d, 12MMSCfd and 18.7MMSCfd), three pipe internal diameters for the two pipe segments (22,24,26-inches OD and 24,26,28-inches OD for segments one and two respectively), and three inlet pressures (57barg, 114barg and 171barg). A total of eighty-one (81) data points were generated and used for the regression analysis in excel.

The outer diameters have been given above because a uniform thickness of approximately 1-inch was used for all pipe sizes. Table 1 shows the system parameters used for the sensitivity analysis.

$\Delta P=f(d 1, d 2, q, P)$ The LINEST (Line estimate) function in Excel was used in developing the correlation. A quadratic fit was used, and the expected results are shown below in equations (2) and (3).

(2)

$\Delta P=d d_{1}{ }^{2}+c d_{2}{ }^{2}+b q^{2}+a P^{2}+h d_{1}+g d_{2}+f q+e P+i$

Where in equations 1 and 2, a, b, c, d, e, f, g, h and I are constants and $d_{1}, d_{2}, q$ and $P$ are pipe- 1 and pipe-2 diameter, gas volumetric flowrate and Inlet pressure respectively. 
Table 1 Sensitivity Analysis Parameters used in PIPESIM

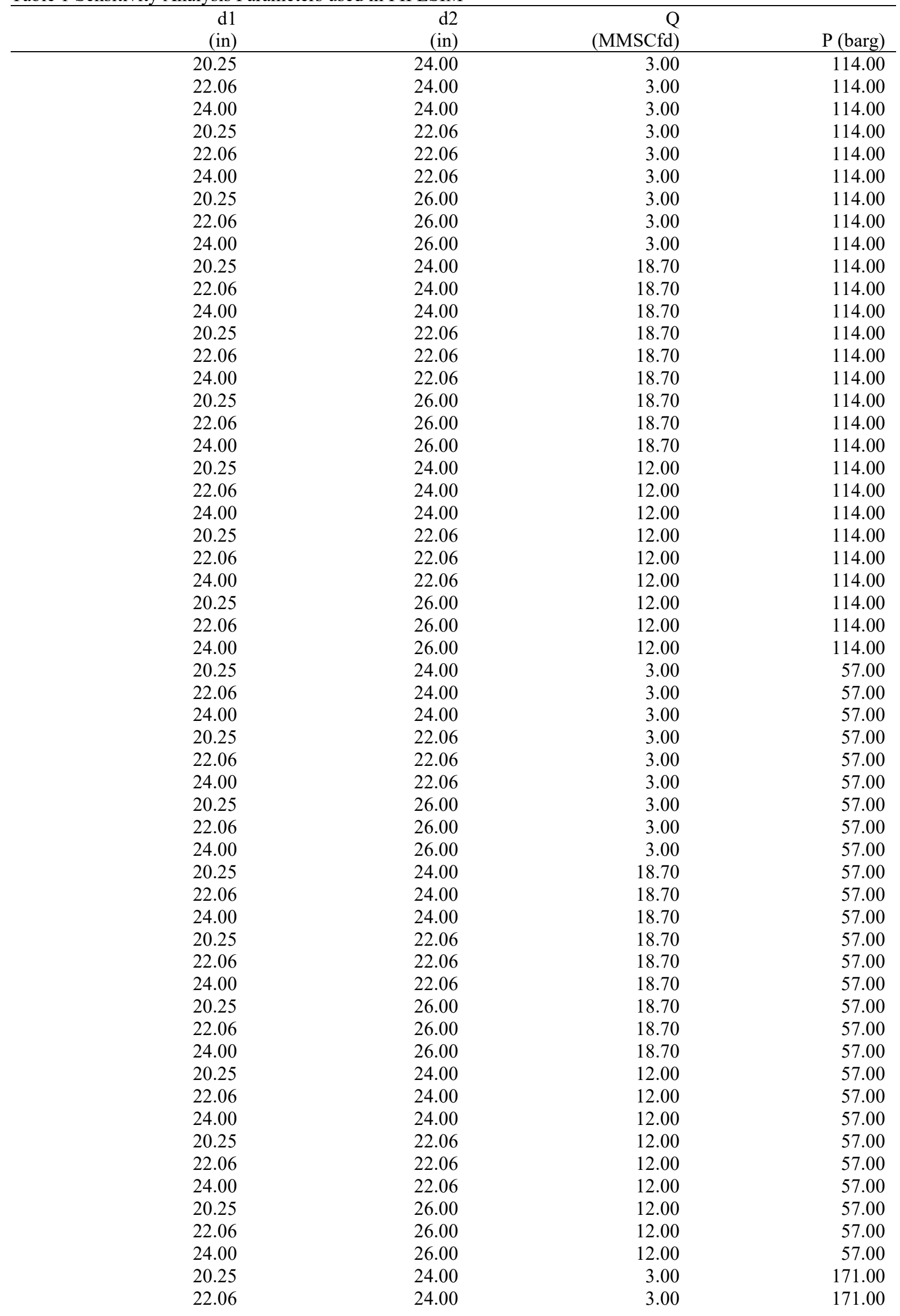




\begin{tabular}{rrrr}
\hline $\mathrm{d} 1$ & $\mathrm{~d} 2$ & $\mathrm{Q}$ & \\
(in) & $(\mathrm{in})$ & $\begin{array}{r}\text { Q } \\
\text { (MMSCfd) }\end{array}$ & 171.00 \\
24.00 & 24.00 & 3.00 & 171.00 \\
20.25 & 22.06 & 3.00 & 171.00 \\
22.06 & 22.06 & 3.00 & 171.00 \\
24.00 & 22.06 & 3.00 & 171.00 \\
20.25 & 26.00 & 3.00 & 171.00 \\
22.06 & 26.00 & 3.00 & 171.00 \\
24.00 & 26.00 & 3.00 & 171.00 \\
20.25 & 24.00 & 18.70 & 171.00 \\
22.06 & 24.00 & 18.70 & 171.00 \\
24.00 & 24.00 & 18.70 & 171.00 \\
20.25 & 22.06 & 18.70 & 171.00 \\
22.06 & 22.06 & 18.70 & 171.00 \\
24.00 & 22.06 & 18.70 & 171.00 \\
20.25 & 26.00 & 18.70 & 171.00 \\
22.06 & 26.00 & 18.70 & 171.00 \\
24.00 & 26.00 & 12.00 & 171.00 \\
20.25 & 24.00 & 12.00 & 171.00 \\
22.06 & 24.00 & 12.00 & 171.00 \\
24.00 & 24.00 & 12.00 & 171.00 \\
20.25 & 22.06 & 12.00 & 171.00 \\
22.06 & 22.06 & 12.00 & 171.00 \\
24.00 & 22.06 & 12.00 & 171.00 \\
20.25 & 26.00 & 12.00 & 171.00 \\
22.06 & 26.00 & 12.00 & 171.00 \\
24.00 & 26.00 & & \\
\hline
\end{tabular}

2.4 Procedure for Regression Analysis with Excel

1. Highlight Nine (9) Columns and five (5) rows in an Excel sheet containing the table values.

2. On the formula bar, click on ' $\mathrm{fx}$ ' and select the LINEST function from the drop-down menu

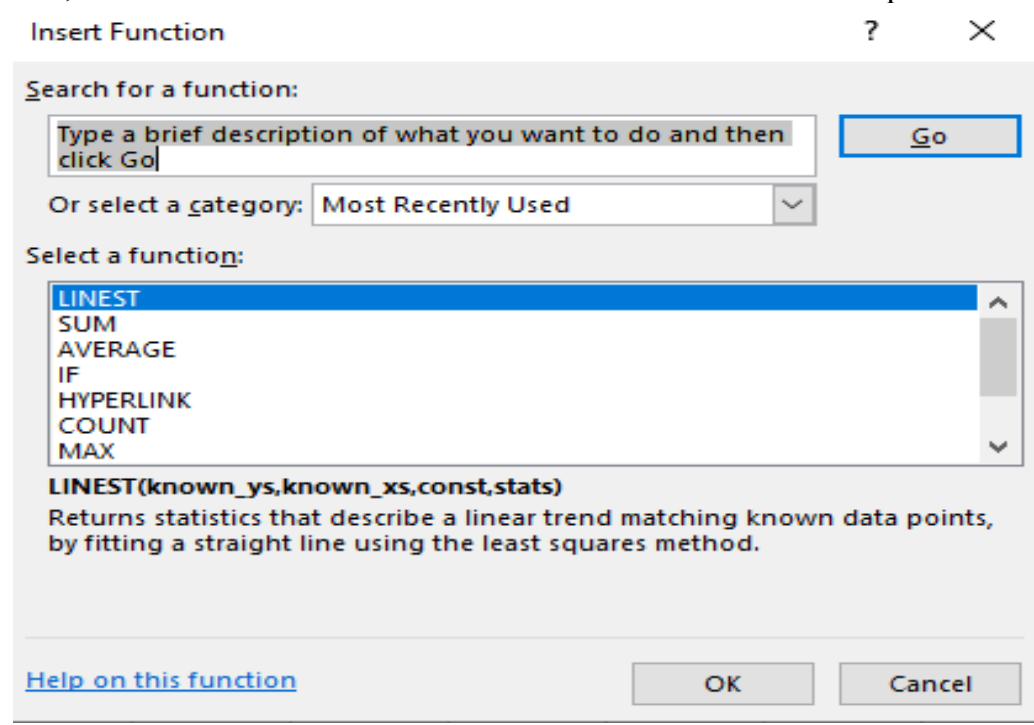

Figure 11 Regression Analysis with LINEST statistics Function in Excel

3. Select the known y (Delta P PIPESIM), known x's (all x values), set logical argument constants=True and stats $=$ True. 


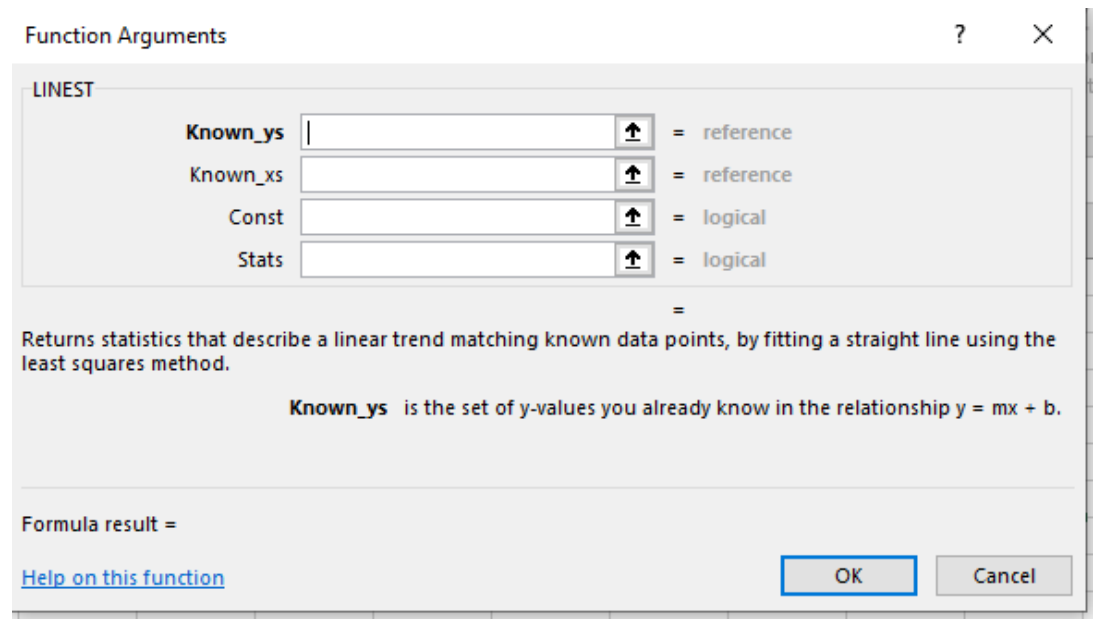

Figure 12 LINEST Statistics function in Excel

1. The displayed results are shown in Table 2 .

Table 2 Typical LINEST Regression Results in Excel

\begin{tabular}{|c|c|c|c|c|c|c|c|c|c|}
\hline 1 & $\mathrm{a}$ & b & $\mathrm{C}$ & $\mathrm{d}$ & e & f & $\mathrm{g}$ & $\mathrm{H}$ & $\mathrm{i}$ \\
\hline 2 & $\mathrm{se}_{\mathrm{n}}$ & $s e_{n-1}$ & $\mathrm{se}_{\mathrm{n}-2}$ & $\mathrm{se}_{\mathrm{n}-3}$ & $s e_{n-4}$ & $\mathrm{se}_{\mathrm{n}-5}$ & $\mathrm{se}_{\mathrm{n}-5}$ & $\mathrm{se}_{\mathrm{n}-6}$ & $\mathrm{se}_{\mathrm{b}}$ \\
\hline 3 & $\mathrm{R}^{2}$ & $\mathrm{se}_{\mathrm{v}}$ & & & & & & & \\
\hline 4 & $\mathrm{~F}$ & $\mathrm{~d}_{\mathrm{f}}$ & & & & & & & \\
\hline 5 & SS $_{\text {reg }}$ & SS $_{\text {resid }}$ & & & & & & & \\
\hline
\end{tabular}

2. Create a column next to Delta P PIPESIM and calculate a new Delta P using the correlation as represented by equation (2).

3. Plot a graph of Delta P PIPESIM against Delta P Calculated. Use scatter points, add a trendline and display $\mathrm{R}^{2}$ value on the chart area.

\section{Results and Discussion}

This section presents and discusses the results obtained from this study. Firstly, Data validation is presented with comparison to the original data source. The simulation results have also been presented, as outlined in the previous section. The result from the sensitivity analysis in Excel has also been presented, and lastly, the developed correlation is presented and validated.

\subsection{Data Validation}

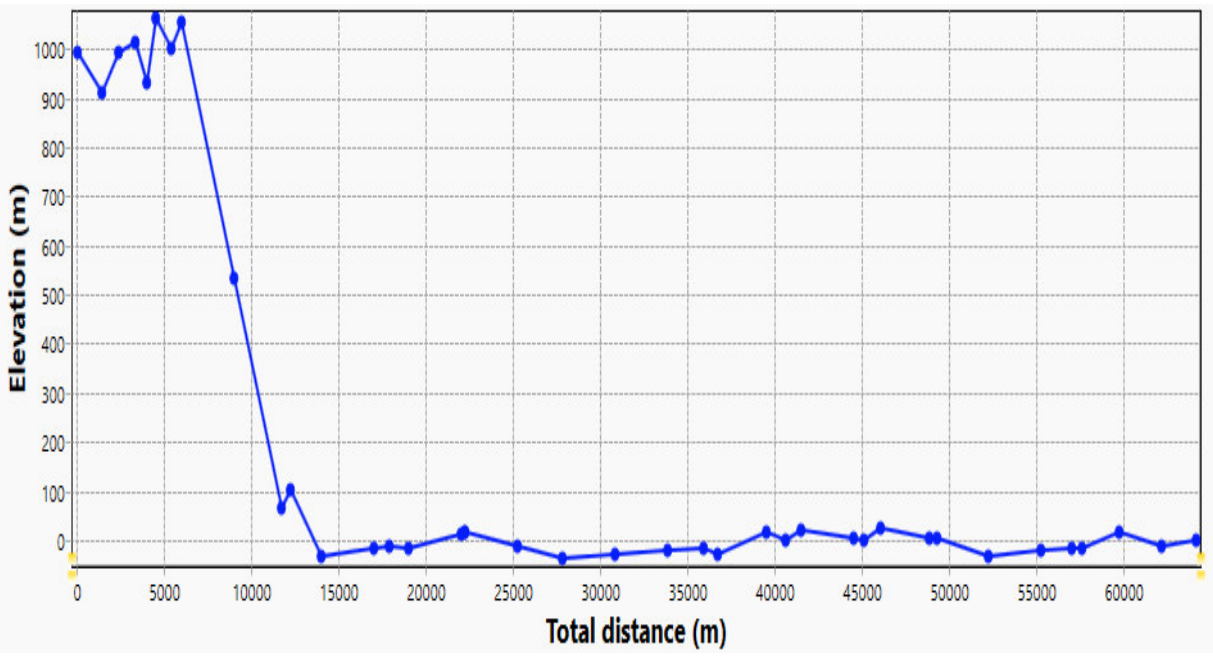

Figure 13 Plot of Pipeline Elevation against Total distance from PIPESIM 


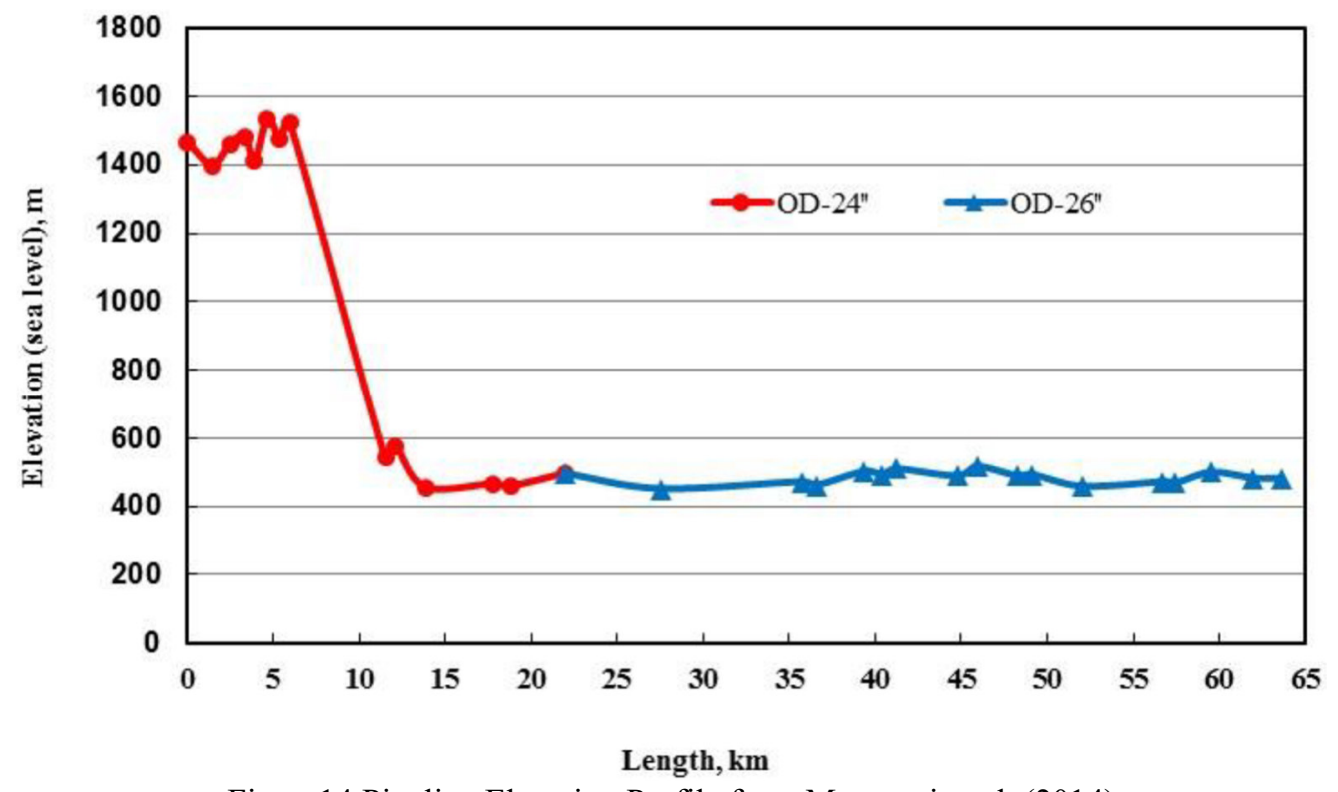

Figure14 Pipeline Elevation Profile from Mansoori et al. (2014)

The profile plot is given in the source, and the resulting profile plot in PIPESIM have been displayed one after the other in Figures 13 and 14, respectively. The observed plot in PIPESIM is the same as that presented in Mansoori et al. (2014).

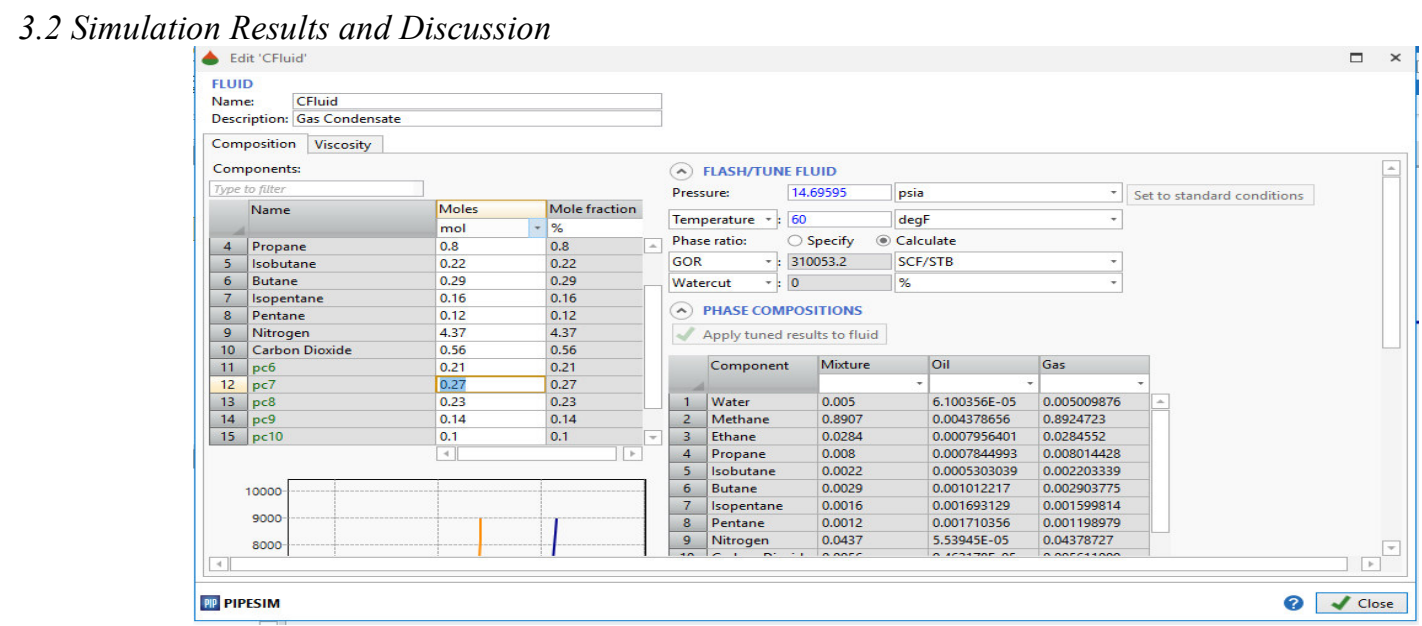

Figure 15 Fluid Composition as built-in PIPESIM

Figure 15 shows the fluid composition built-in PIPESIM software. The components in dark components are pure, and those in green are pseudo-components. Pseudo-components were added by defining their molecular weights and liquid densities. 


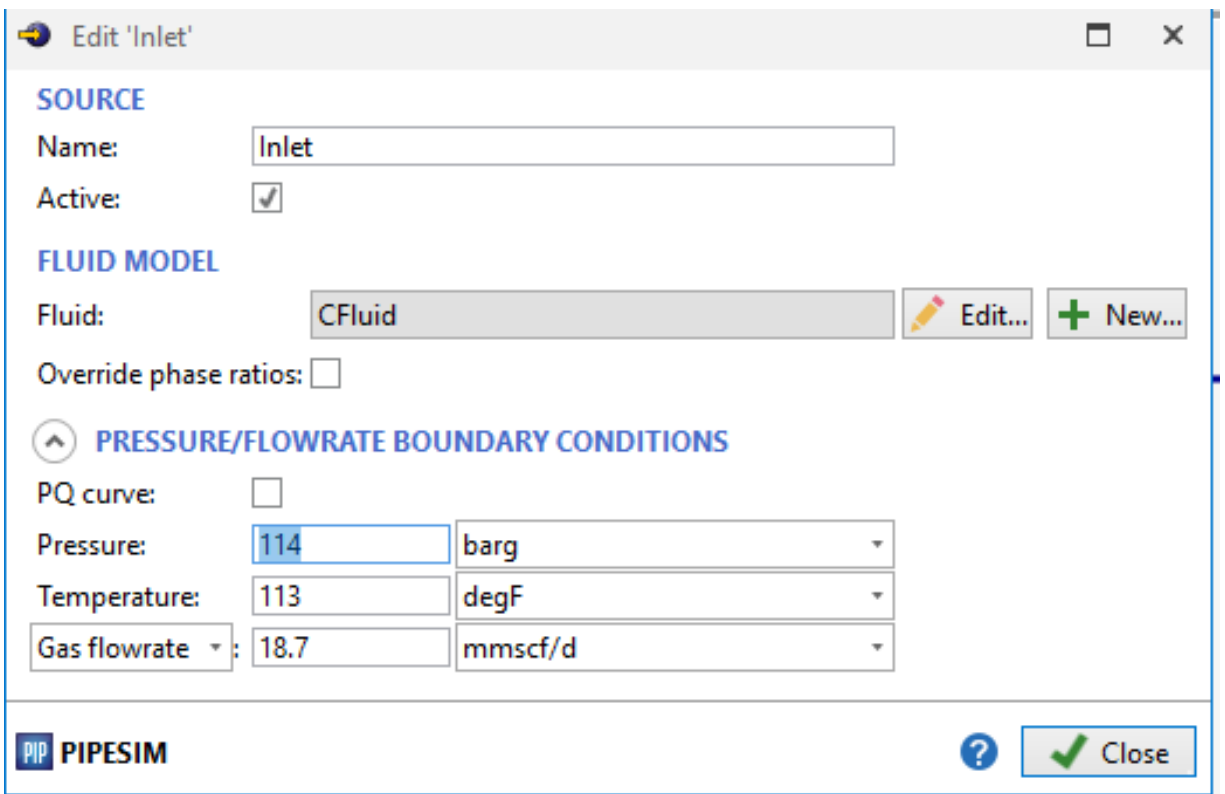

Figure 16 Definition of Initial Conditions in PIPESIM

Figure 16 shows the definition of system initial condition of pressure, temperature and gas volumetric flowrates.

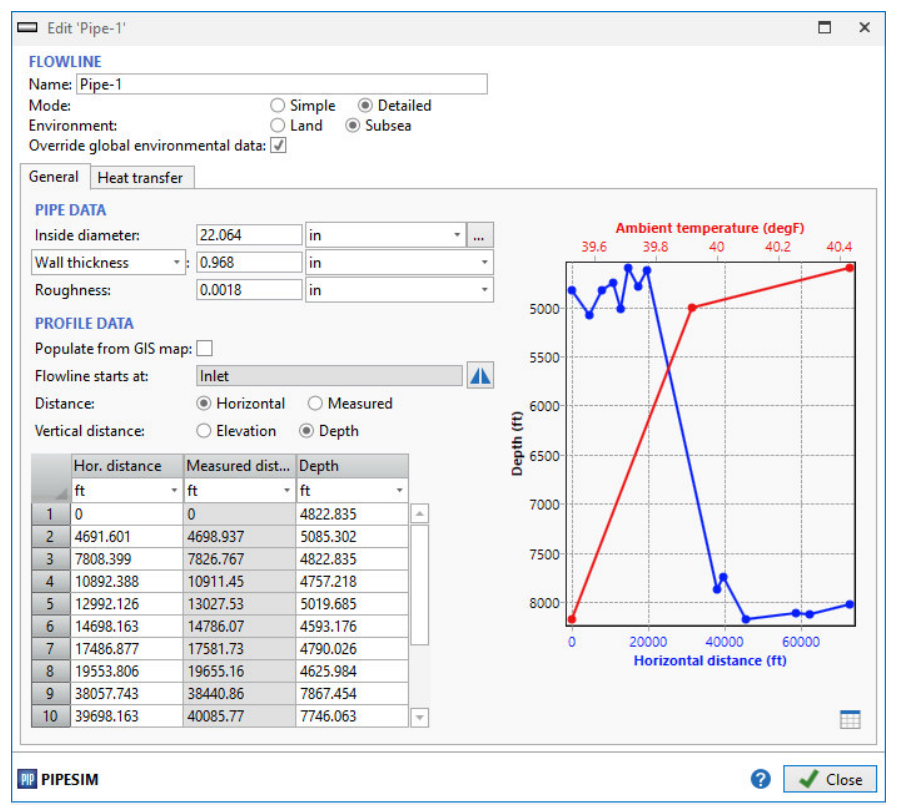

Figure 17 Pipe-1 detailed profile in PIPESIM for the base case

Figure 17 shows the detailed profile of Pipe-1 in the simulation model. The depth and horizontal distances, as seen in the figure. The internal pipe diameter was selected from the American Petroleum Institute (API) catalogue based on the outer diameter of 24-inches and the criteria of having approximately 1-inch thickness since the transported fluid predominantly gas. The API catalogue is in-built in the software, and the previous section illustrates how to select the pipe size using the catalogue 


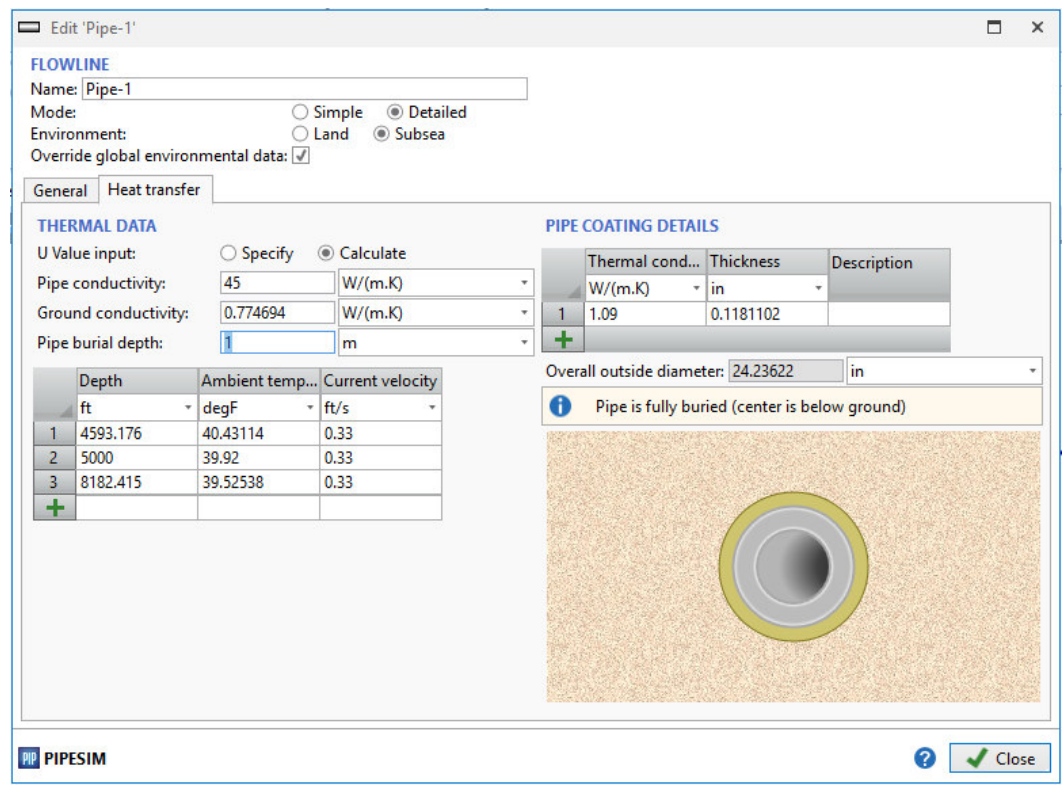

Figure 18 Pipe-1 Heat transfer data in PIPESIM for the base case

Figure 18 shows the heat transfer data used in the simulation. The calculate option was used for the heat transfer. Pipe conductivity and ground conductivity were default values for carbon steel and the location, respectively. Pipe coating details and burial depth were specified, and the thermal conductivity of the insulation material (polyethene) was sourced from an engineering data book.

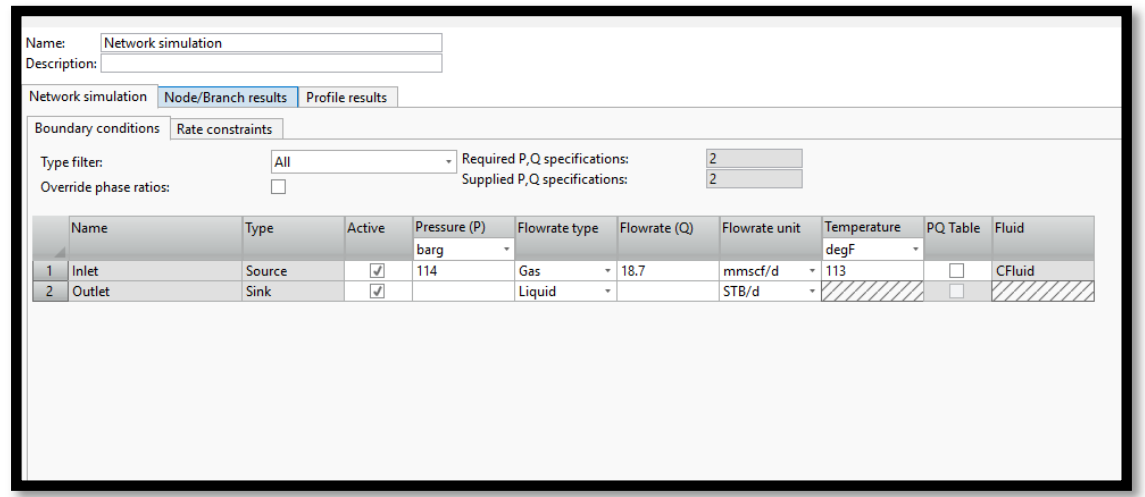

Figure 19 Network Simulation Window with Initial Conditions Specified

Figure 19 shows the network simulation window wherein initial conditions of the fluid were supplied before running the simulation. As seen from Figure 19, at least two process parameters (pressure and flow rate in this case) were specified for the simulation to run. For this case, the inlet pressure (114barg) and gas volumetric flowrate (18.7MMSCfd) was supplied. The engine console output for the simulation.

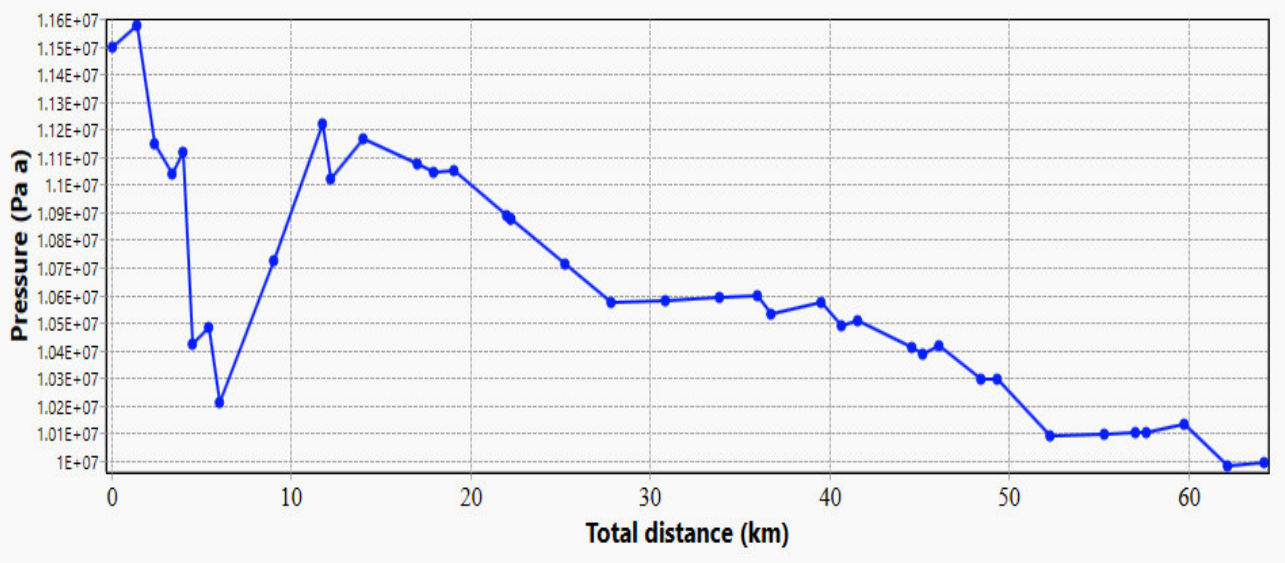

Figure 20 Plot of Pressure against Total distance at 18.7MMSCfd Flowrate 
The pressure of the system was plotted against profile using different scenarios. Sensitivity and System Analysis were also performed to determine the system's response to different operational scenarios. Figure 20 shows a plot of Pressure against the total distance at a gas flowrate of 18.7MMSCfd and shows how the system inlet pressure drops as the flow progresses through the length. For the total length 13.804barg (1.38MPa) pressure was lost in the system compared to $18.2 \mathrm{barg}(18.2 \mathrm{MPa})$. This is $24.2 \%$ deviation could have resulted from properties used in the simulation that was not given in the original work. These properties were estimated and sourced otherwise. The pressure drop experienced can be attributed to the nature of flow which alternates between Stratified and Intermittent flow as well as the pipe roughness and terrain of the pipeline route.

\subsection{Correlation Results}

System sensitivity analysis was also performed for the system using a different combination of pipe diameters for segments, gas volumetric flowrates and Inlet pressure, as shown in Table 1. The trend showed a minor difference in pressure drop between high and low gas flow rates, as shown in Table 3.

The quadratic fit was done on the sensitivity data in Table 1. Table 2 shows the correlation result using the LINEST function in Excel. The displayed values when compared with the table in step 4 of section 2.2.1 gives the following;

$a=-0.0004, b=-0.0139, c=-0.0027, d=-0.0043, e=-0.0526, f=-0.0968, g=0.23342, h=$ 0.43971 , and $i=19.8346$.

The $\mathrm{R}^{2}=0.92265$, which is close to one and the correlation to an extension can be used in predicting pressure drop. Table 3 PIPESIM Sensitivity Analysis Results

\begin{tabular}{|c|c|c|c|c|c|c|c|c|c|}
\hline $\begin{array}{l}\Delta \mathrm{P}_{\text {Calculated }} \\
\text { (barg) }\end{array}$ & $\begin{array}{l}\Delta \text { PPIPESIM } \\
\text { (barg) }\end{array}$ & $\begin{array}{l}\mathrm{d} 1 \\
\text { (in) }\end{array}$ & $\begin{array}{l}\mathrm{d} 2 \\
\text { (in) }\end{array}$ & $\begin{array}{l}\text { Q } \\
\text { (MMSCfd) }\end{array}$ & P (barg) & $\begin{array}{l}d 1^{\wedge} 2 \\
(\mathrm{in} \wedge 2) \\
\end{array}$ & $\begin{array}{l}\mathrm{d} 2^{\wedge} 2 \\
\left(\mathrm{in}^{\wedge} 2\right) \\
\end{array}$ & $\begin{array}{l}\mathrm{q}^{\wedge} 2 \\
(\mathrm{MMSCfd})^{\wedge} 2\end{array}$ & $\begin{array}{l}P^{\wedge} 2 \\
(\text { barg)^2 }\end{array}$ \\
\hline 20.0911 & 20.1000 & 20.25 & 24.00 & 3.00 & 114.00 & 410.06 & 576.00 & 9.00 & 12996 \\
\hline 20.5626 & 20.2400 & 22.06 & 24.00 & 3.00 & 114.00 & 486.82 & 576.00 & 9.00 & 12996 \\
\hline 19.4137 & 20.3700 & 24.00 & 24.00 & 3.00 & 114.00 & 576.00 & 576.00 & 9.00 & 12996 \\
\hline 19.8844 & 20.0200 & 20.25 & 22.06 & 3.00 & 114.00 & 410.06 & 486.82 & 9.00 & 12996 \\
\hline 20.3559 & 20.1800 & 22.06 & 22.06 & 3.00 & 114.00 & 486.82 & 486.82 & 9.00 & 12996 \\
\hline 19.8122 & 20.3300 & 24.00 & 22.06 & 3.00 & 114.00 & 576.00 & 486.82 & 9.00 & 12996 \\
\hline 20.2830 & 20.1400 & 20.25 & 26.00 & 3.00 & 114.00 & 410.06 & 676.00 & 9.00 & 12996 \\
\hline 20.7544 & 20.3100 & 22.06 & 26.00 & 3.00 & 114.00 & 486.82 & 676.00 & 9.00 & 12996 \\
\hline 13.3804 & 20.4400 & 24.00 & 26.00 & 3.00 & 114.00 & 576.00 & 676.00 & 9.00 & 12996 \\
\hline 13.8511 & 13.3100 & 20.25 & 24.00 & 18.70 & 114.00 & 410.06 & 576.00 & 349.69 & 12996 \\
\hline 14.3226 & 14.0600 & 22.06 & 24.00 & 18.70 & 114.00 & 486.82 & 576.00 & 349.69 & 12996 \\
\hline 13.1737 & 14.7200 & 24.00 & 24.00 & 18.70 & 114.00 & 576.00 & 576.00 & 349.69 & 12996 \\
\hline 13.6444 & 13.0600 & 20.25 & 22.06 & 18.70 & 114.00 & 410.06 & 486.82 & 349.69 & 12996 \\
\hline 14.1159 & 13.8100 & 22.06 & 22.06 & 18.70 & 114.00 & 486.82 & 486.82 & 349.69 & 12996 \\
\hline 13.5722 & 14.4600 & 24.00 & 22.06 & 18.70 & 114.00 & 576.00 & 486.82 & 349.69 & 12996 \\
\hline 14.0430 & 13.5300 & 20.25 & 26.00 & 18.70 & 114.00 & 410.06 & 676.00 & 349.69 & 12996 \\
\hline 14.5144 & 14.2900 & 22.06 & 26.00 & 18.70 & 114.00 & 486.82 & 676.00 & 349.69 & 12996 \\
\hline 16.8789 & 14.9400 & 24.00 & 26.00 & 18.70 & 114.00 & 576.00 & 676.00 & 349.69 & 12996 \\
\hline 17.3496 & 16.4800 & 20.25 & 24.00 & 12.00 & 114.00 & 410.06 & 576.00 & 144.00 & 12996 \\
\hline 17.8211 & 17.0500 & 22.06 & 24.00 & 12.00 & 114.00 & 486.82 & 576.00 & 144.00 & 12996 \\
\hline 16.6722 & 17.5400 & 24.00 & 24.00 & 12.00 & 114.00 & 576.00 & 576.00 & 144.00 & 12996 \\
\hline 17.1430 & 16.2700 & 20.25 & 22.06 & 12.00 & 114.00 & 410.06 & 486.82 & 144.00 & 12996 \\
\hline 17.6144 & 16.8400 & 22.06 & 22.06 & 12.00 & 114.00 & 486.82 & 486.82 & 144.00 & 12996 \\
\hline 17.0707 & 17.3200 & 24.00 & 22.06 & 12.00 & 114.00 & 576.00 & 486.82 & 144.00 & 12996 \\
\hline 17.5415 & 16.6900 & 20.25 & 26.00 & 12.00 & 114.00 & 410.06 & 676.00 & 144.00 & 12996 \\
\hline 18.0130 & 17.2600 & 22.06 & 26.00 & 12.00 & 114.00 & 486.82 & 676.00 & 144.00 & 12996 \\
\hline 26.3537 & 17.7400 & 24.00 & 26.00 & 12.00 & 114.00 & 576.00 & 676.00 & 144.00 & 12996 \\
\hline 26.8244 & 29.8400 & 20.25 & 24.00 & 3.00 & 57.00 & 410.06 & 576.00 & 9.00 & 3249 \\
\hline 27.2959 & 30.2400 & 22.06 & 24.00 & 3.00 & 57.00 & 486.82 & 576.00 & 9.00 & 3249 \\
\hline 26.1470 & 30.5700 & 24.00 & 24.00 & 3.00 & 57.00 & 576.00 & 576.00 & 9.00 & 3249 \\
\hline 26.6178 & 29.6200 & 20.25 & 22.06 & 3.00 & 57.00 & 410.06 & 486.82 & 9.00 & 3249 \\
\hline 27.0893 & 30.0200 & 22.06 & 22.06 & 3.00 & 57.00 & 486.82 & 486.82 & 9.00 & 3249 \\
\hline 26.5456 & 30.3500 & 24.00 & 22.06 & 3.00 & 57.00 & 576.00 & 486.82 & 9.00 & 3249 \\
\hline 27.0163 & 30.0200 & 20.25 & 26.00 & 3.00 & 57.00 & 410.06 & 676.00 & 9.00 & 3249 \\
\hline 27.4878 & 30.4200 & 22.06 & 26.00 & 3.00 & 57.00 & 486.82 & 676.00 & 9.00 & 3249 \\
\hline 20.1137 & 30.7600 & 24.00 & 26.00 & 3.00 & 57.00 & 576.00 & 676.00 & 9.00 & 3249 \\
\hline 20.5844 & 17.4100 & 20.25 & 24.00 & 18.70 & 57.00 & 410.06 & 576.00 & 349.69 & 3249 \\
\hline 21.0559 & 18.4900 & 22.06 & 24.00 & 18.70 & 57.00 & 486.82 & 576.00 & 349.69 & 3249 \\
\hline 19.9070 & 19.4900 & 24.00 & 24.00 & 18.70 & 57.00 & 576.00 & 576.00 & 349.69 & 3249 \\
\hline 20.3778 & 16.9700 & 20.25 & 22.06 & 18.70 & 57.00 & 410.06 & 486.82 & 349.69 & 3249 \\
\hline 20.8493 & 18.0500 & 22.06 & 22.06 & 18.70 & 57.00 & 486.82 & 486.82 & 349.69 & 3249 \\
\hline
\end{tabular}




\begin{tabular}{|c|c|c|c|c|c|c|c|c|c|}
\hline 20.3056 & 19.0500 & 24.00 & 22.06 & 18.70 & 57.00 & 576.00 & 486.82 & 349.69 & 3249 \\
\hline 20.7763 & 17.8100 & 20.25 & 26.00 & 18.70 & 57.00 & 410.06 & 676.00 & 349.69 & 3249 \\
\hline 21.2478 & 18.8900 & 22.06 & 26.00 & 18.70 & 57.00 & 486.82 & 676.00 & 349.69 & 3249 \\
\hline 23.6122 & 19.9000 & 24.00 & 26.00 & 18.70 & 57.00 & 576.00 & 676.00 & 349.69 & 3249 \\
\hline 24.0830 & 21.9300 & 20.25 & 24.00 & 12.00 & 57.00 & 410.06 & 576.00 & 144.00 & 3249 \\
\hline 24.5544 & 22.8700 & 22.06 & 24.00 & 12.00 & 57.00 & 486.82 & 576.00 & 144.00 & 3249 \\
\hline 23.4056 & 23.7100 & 24.00 & 24.00 & 12.00 & 57.00 & 576.00 & 576.00 & 144.00 & 3249 \\
\hline 23.8763 & 21.4900 & 20.25 & 22.06 & 12.00 & 57.00 & 410.06 & 486.82 & 144.00 & 3249 \\
\hline 24.3478 & 22.4200 & 22.06 & 22.06 & 12.00 & 57.00 & 486.82 & 486.82 & 144.00 & 3249 \\
\hline 23.8041 & 23.2600 & 24.00 & 22.06 & 12.00 & 57.00 & 576.00 & 486.82 & 144.00 & 3249 \\
\hline 24.2748 & 22.3300 & 20.25 & 26.00 & 12.00 & 57.00 & 410.06 & 676.00 & 144.00 & 3249 \\
\hline 24.7463 & 23.2700 & 22.06 & 26.00 & 12.00 & 57.00 & 486.82 & 676.00 & 144.00 & 3249 \\
\hline 10.3956 & 24.1200 & 24.00 & 26.00 & 12.00 & 57.00 & 576.00 & 676.00 & 144.00 & 3249 \\
\hline 10.8663 & 7.3800 & 20.25 & 24.00 & 3.00 & 171.00 & 410.06 & 576.00 & 9.00 & 29241 \\
\hline 11.3378 & 7.2900 & 22.06 & 24.00 & 3.00 & 171.00 & 486.82 & 576.00 & 9.00 & 29241 \\
\hline 10.1889 & 7.3200 & 24.00 & 24.00 & 3.00 & 171.00 & 576.00 & 576.00 & 9.00 & 29241 \\
\hline 10.6596 & 7.3500 & 20.25 & 22.06 & 3.00 & 171.00 & 410.06 & 486.82 & 9.00 & 29241 \\
\hline 11.1311 & 7.2600 & 22.06 & 22.06 & 3.00 & 171.00 & 486.82 & 486.82 & 9.00 & 29241 \\
\hline 10.5874 & 7.2900 & 24.00 & 22.06 & 3.00 & 171.00 & 576.00 & 486.82 & 9.00 & 29241 \\
\hline 11.0581 & 7.4000 & 20.25 & 26.00 & 3.00 & 171.00 & 410.06 & 676.00 & 9.00 & 29241 \\
\hline 11.5296 & 7.3100 & 22.06 & 26.00 & 3.00 & 171.00 & 486.82 & 676.00 & 9.00 & 29241 \\
\hline 4.1556 & 7.3400 & 24.00 & 26.00 & 3.00 & 171.00 & 576.00 & 676.00 & 9.00 & 29241 \\
\hline 4.6263 & 6.1500 & 20.25 & 24.00 & 18.70 & 171.00 & 410.06 & 576.00 & 349.69 & 29241 \\
\hline 5.0978 & 6.5900 & 22.06 & 24.00 & 18.70 & 171.00 & 486.82 & 576.00 & 349.69 & 29241 \\
\hline 3.9489 & 6.9600 & 24.00 & 24.00 & 18.70 & 171.00 & 576.00 & 576.00 & 349.69 & 29241 \\
\hline 4.4196 & 6.0800 & 20.25 & 22.06 & 18.70 & 171.00 & 410.06 & 486.82 & 349.69 & 29241 \\
\hline 4.8911 & 6.4600 & 22.06 & 22.06 & 18.70 & 171.00 & 486.82 & 486.82 & 349.69 & 29241 \\
\hline 4.3474 & 6.9400 & 24.00 & 22.06 & 18.70 & 171.00 & 576.00 & 486.82 & 349.69 & 29241 \\
\hline 4.8181 & 6.2600 & 20.25 & 26.00 & 18.70 & 171.00 & 410.06 & 676.00 & 349.69 & 29241 \\
\hline 5.2896 & 6.6900 & 22.06 & 26.00 & 18.70 & 171.00 & 486.82 & 676.00 & 349.69 & 29241 \\
\hline 7.6541 & 7.0600 & 24.00 & 26.00 & 18.70 & 171.00 & 576.00 & 676.00 & 349.69 & 29241 \\
\hline 8.1248 & 9.5700 & 20.25 & 24.00 & 12.00 & 171.00 & 410.06 & 576.00 & 144.00 & 29241 \\
\hline 8.5963 & 9.5900 & 22.06 & 24.00 & 12.00 & 171.00 & 486.82 & 576.00 & 144.00 & 29241 \\
\hline 7.4474 & 9.9400 & 24.00 & 24.00 & 12.00 & 171.00 & 576.00 & 576.00 & 144.00 & 29241 \\
\hline 7.9181 & 9.4500 & 20.25 & 22.06 & 12.00 & 171.00 & 410.06 & 486.82 & 144.00 & 29241 \\
\hline 8.3896 & 9.4600 & 22.06 & 22.06 & 12.00 & 171.00 & 486.82 & 486.82 & 144.00 & 29241 \\
\hline 7.8459 & 9.8200 & 24.00 & 22.06 & 12.00 & 171.00 & 576.00 & 486.82 & 144.00 & 29241 \\
\hline 8.3167 & 9.7000 & 20.25 & 26.00 & 12.00 & 171.00 & 410.06 & 676.00 & 144.00 & 29241 \\
\hline 8.7881 & 9.7100 & 22.06 & 26.00 & 12.00 & 171.00 & 486.82 & 676.00 & 144.00 & 29241 \\
\hline 19.8346 & 10.0600 & 24.00 & 26.00 & 12.00 & 171.00 & 576.00 & 676.00 & 144.00 & 29241 \\
\hline
\end{tabular}

Table 4 LINEST Regression Result in Excel

\begin{tabular}{rrrrrrrrrc}
\hline 1 & -0.0004 & -0.0139 & -0.0027 & -0.0043 & -0.0526 & -0.0968 & 0.23342 & 0.43971 & 19.8346 \\
2 & 0.00016 & 0.00847 & 0.13151 & 0.14501 & 0.0361 & 0.18455 & 6.32403 & 6.42168 & 103.687 \\
3 & 0.92265 & 2.16028 & \#N/A & \#N/A & \#N/A & \#N/A & \#N/A & \#N/A & \#N/A \\
4 & 107.361 & 72 & \#N/A & \#N/A & \#N/A & \#N/A & \#N/A & \#N/A & \#N/A \\
5 & 4008.24 & 336.009 & \#N/A & \#N/A & \#N/A & \#N/A & \#N/A & \#N/A & \#N/A \\
\hline
\end{tabular}

The correlation was developed with data from the system sensitivity analysis, and the data is presented in table 3. Using equation 3, the pressure drop correlation from this present study is presented in equation $\Delta P=-0.0526 d_{1}{ }^{2}-0.0968 d_{2}{ }^{2}+0.23342 q^{2}+0.43971 P^{2}$

$$
-0.0004 d_{1}-0.0139 d_{2}-0.0027 q-0.0043 P+19.8346
$$

A new pressure drop was calculated using the above correlation, and the results are presented in column 1 of Table 3. The estimated results showed good agreement with the predicted pressure drop from PIPESIM. A plot of the predicted value versus Calculated value is shown in figure 21. 


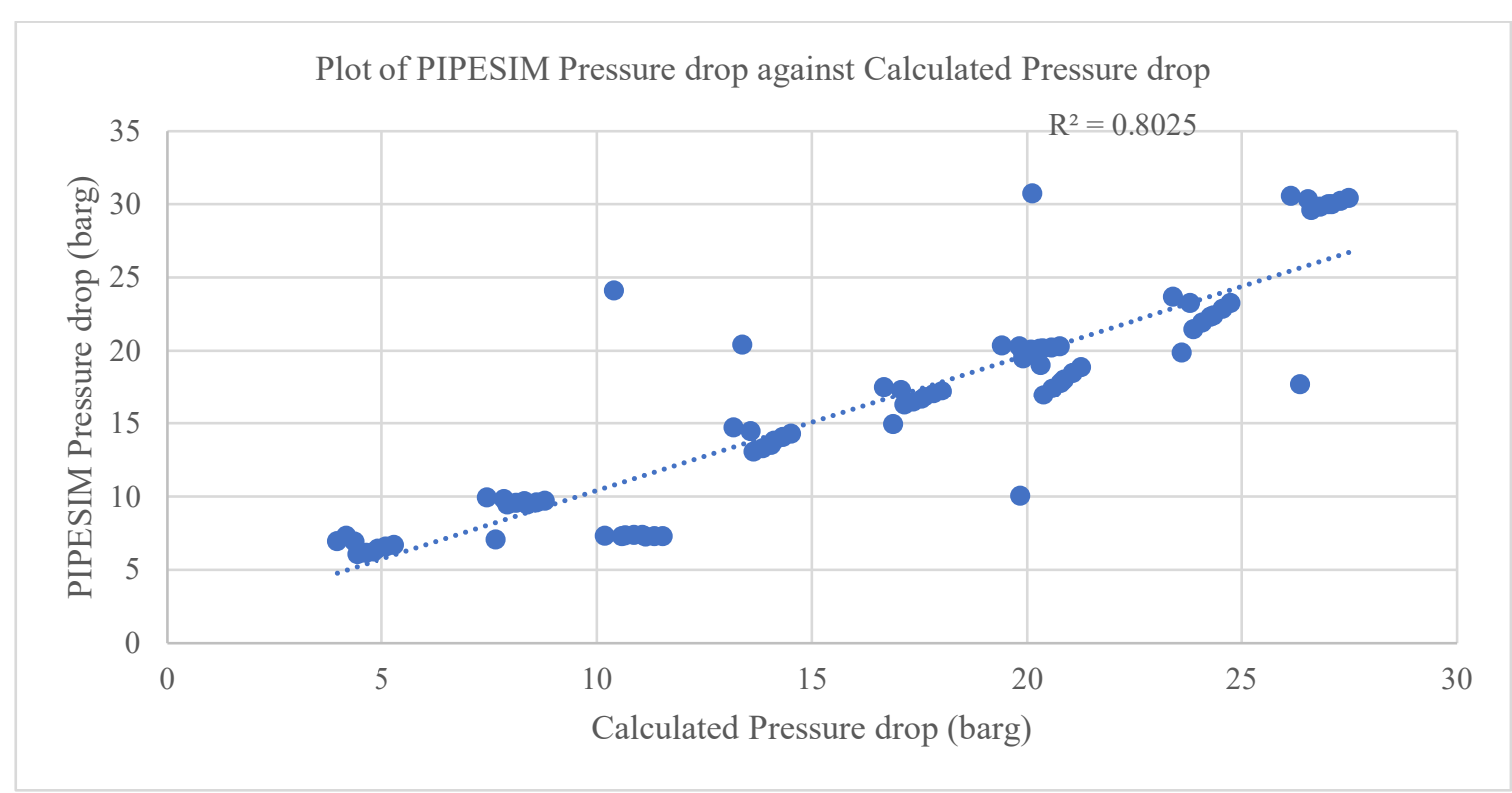

Figure 21 Plot of Predicted Pressure drop against Calculated Pressure drop

Figure 21 is a plot of PIPESIM predicted pressure drop against the calculated pressure drop. Point The data points are very close to the trendline showing good approximation. The displayed $\mathrm{R}^{2}$ value of 0.8025 is close to the value one, and hence the correlation is a good approximation of the software values.

\section{CONCLUSION AND RECOMMENDATION \\ 4.1 CONCLUSION}

The results obtained showed that pressure drop occurs during multiphase flow and the amount of pressure drop observed was largely dependent on pipeline inlet pressure, flowrates, and internal pipe diameters. 13.8barg (13.8MPa) was lost in the system for the base case simulation, as shown in Figure 20. Sensitivity Analysis was done on process parameters such as inlet pressure, gas volumetric flowrate and segment pipe internal diameter showed that at the high flowrate and high inlet pressure. The pressure-drop observed was minimal and vice versa (see Table 3). Another deduction from the study was that at constant flowrates and inlet pressures, the pressure drop was observed to increase with increasing size of the internal pipe diameter. The resulting $\mathrm{R}^{2}$ value of 0.9226 was obtained from this analysis, as shown in Table 4, which is acceptable. The plot of Predicted Pressure-drop against Calculated pressure-drop similarly gave an $\mathrm{R}^{2}$ value of 0.8025 with five out outliers. The coefficient of determination $\left(\mathrm{R}^{2}\right)$ in both cases is close to 1; hence the developed correlation can be used as an estimate in the absence of the PIPESIM software for pressure drop prediction purposes

PIPESIM was used in this study for the modelling and simulation, and the results showed that PIPESIM as a tool is effective for multiphase flow simulation. Sensitivity analysis performed and model developed can be used in place of the software for pressure drop estimation in the events that there is no access to the software.

The study revealed that pressure drop will always occur during the transport of multiphase fluid. The amount of pressure drop experienced is depended on certain process parameters such as pipeline length, flowrates, Inlet pressure, internal pipe diameter etc. From Table 3, it was observed that the pressure losses experienced at high inlet pressures and high flowrates were lowest. The highest-pressure drops were experienced at low inlet pressure and high flowrates. It was also observed that for the same flowrates and inlet pressures, the higher the internal pipe diameter, the greater the pressure losses

\subsection{RECOMMENDATION}

Pipeline length (the distance of travel) is a critical factor in pressure drop estimation. This work did not consider the distance of travel in the correlation developed and the minute difference in the predicted and calculated values may be due to this reason. Therefore, it is recommended that subsequent studies take into consideration the distance of travel in developing the pressure drop correlation. The model developed in this study was only tested using the same data from which it was developed due to the unavailability of real data. Therefore, it is also recommended that the pressure drop correlation be tested with real data. Lastly, OLGA software should be used for this same study to find out if there would be an agreement between the two models developed using the two different software. The regression analysis was done using a quadratic equation which could also have affected the value of the calculated pressure drop. Therefore, it is recommended that higher polynomials be used in further studies.

This study established that the multiphase simulators can effectively predict the pressure drop in the multiphase flow systems. PIPESIM was used for this study and the results obtained were acceptable. This work established a 
laid down procedure for simulating multiphase flowline with PIPESIM, which is valuable to upcoming Engineers and students alike as it prepares them for the industry. The correlation developed can serve as a quick resource for estimating the pressure drop in subsea flowlines if the PIPESIM software is inaccessible.

\section{References}

Asante, B. (2000). Multiphase Transport of gas and Low Loads of Liquids in Pipelines. Unpublished doctoral dissertation, University of Calgary.

Awad, M. M., \& Muzychka, Y. S. (2004). A Simple Asymptotic Compact Model for Two-Phase Frictional Pressure Gradient in Horizontal Pipes. Fluids Engineering. doi:10.1115/imece2004-61410

Badie, S., Hale, C.P., Lawrence, C.J., Hewitt, G.F., (2000). Pressure gradient and holdup in horizontal two-phase gas-liquid flows with low liquid loading. Int. J. Multiphase Flow 26 (9), 1525-1543.

Bai, Y. and Bai, Q. (2010), Subsea Engineering Handbook, Elsevier, Massachusetts, USA.

Beggs H. D. and Brill J. P. (1973). "A Study of Two-Phase Flow in Inclined Pipes”, J. Pet. Tech. May $607-617$.

Bhagwat, S. M., \& Ghajar, A. J. (2015). Modified liquid entrainment fraction correlation for varying pipe orientation and system pressure. International Journal of Multiphase Flow, 74, 1-4. doi: 10.1016/j.ijmultiphaseflow.2015.04.001

Danielson, T. J., Brown, L. D., \& Bansal, K. M. (2000). Flow Management: Steady-State and Transient Multiphase Pipeline Simulation. In Offshore Technology Conference. Offshore Technology Conference.

Danielson, T.J., Bansal, K.M., Djoric B., Duret E.-D., Johansen, S.T., Hellan O. (2011). Testing and Qualification of a New Multiphase Flow Simulator. Offshore Technology Conference.

Duns Jr., H., Ros, N.C.J., (1963). Vertical flow of gas and liquid mixtures from boreholes. Proceedings of the Sixth World Petroleum Congress, Frankfurt, Sect. II: Paper, 22.PD6.

Engineering Data Book 111, Wolverine Tube, Inc., (2006), Engineering Thermal Innovation.

Fan, Y. (2005) "An investigation of low-liquid-loading gas-liquid stratified flow in near-horizontal pipes." $\mathrm{PhD}$ Dissertation, University of Tulsa, Oklahoma, USA.

Gawas, K. (2013) "Studies in low-liquid loading in gas/oil/water three-phase flow in horizontal and near-horizontal pipes." PhD Dissertation, University of Tulsa, Oklahoma, USA.

Hagedorn A. R. and Brown K. E. (1964). "The Effect of Liquid Viscosity in Two-Phase VerticalFlow", J. Pet. Tech., February 203-210.

Hamad, F. A., Faraji, F., Santim, C. G. S., Basha, N., \& Ali, Z. (2017). Investigation of pressure drop in horizontal pipes with different diameters. International Journal of Multiphase Flow, 91, 120-129.

Https://www.software.slb.com/products/pipesim/pipesim-flowmodeling, 27 $7^{\text {th }}$ September 2019.

Https://www.software.slb.com/products/olga/olga-flowmodeling, $27^{\text {th }}$ September 2019.

Lakehal, D. (2013). Advanced simulation of transient multiphase flow \& flow assurance in the oil \& gas industry. The Canadian Journal of Chemical Engineering, 91(7), 1201-1214.

Lockhart, R.W. and Martinelli, R.C., (January 1949) Proposed Correlation of Data for Isothermal Two-Phase, Two-Component Flow in Pipes, Chemical Engineering Progress p. 39-48.

Mansoori, H., Mobedifard, V., Kouhpeyma, A. M., \& Mohammadi, A. H. (2014). Study finds simulation flaws in multiphase environment. Oil Gas J, 112(11), 102-105.

Mantilla, I., Viana, F., Kouba, G., Roberts, R. (2012) "Experimental investigation of liquid entrainment in gas at high pressure. " In Proceedings of the 8th North American Conference on Multiphase Technology, BHR Group 2012 Multiphase 8, Banff, Alberta, Canada, 20-22 June.

Mukherjee, H., \& Brill, J. P. (1985). Empirical equations to predict flow patterns in two-phase inclined flow. International journal of multiphase flow, 11(3), 299-315.

Musaab M. Ahmed and Mohammed A. Ayoub (2014). A Comprehensive Study on the Current Pressure Drop Calculation in Multiphase Vertical Wells; Current Trends and Future Prospective. Journal of Applied Sciences, 14: 3162-3171.

Olive, N. R., Zhang, H. Z., Redus, C. L. and Brill, J. P. (2003). Experimental Study of Low Liquid Loading GasLiquid Flow in Near-Horizontal Pipes", Journal of Energy Resources Technology, Vol. 125, 294-298.

Orkiszewski J. (1967). "Predicting Two Phase Pressure Drops in Vertical Pipe”,J. Pet. Tech.,June,829-838.

Petalas, N., and Aziz, K. (2000). A mechanistic model for multiphase flow in pipes. Journal of Canadian Petroleum Technology, 39(06).

Taitel, Y., (1994), Advances in Two-Phase Flow Modeling. Society of Petroleum Engineers, SPE 27959-MS, January 1.

Thomas S. Ameel T. Guilkey J. (2010). Mixing kinematics of moderate Reynolds number flows in a T-channel. Phys Fluids 2010]; 22:013601.

Tine B., I. Jacobsen, B. Hægland and A. Sanchis (2015). FMC TECHNOLOGIES. Flow Assurance \& Operability, A System Perspective, Revision 5, MEK 4450 
Trangenstein, J. A., \& Bell, J. B. (1989). Mathematical structure of the black-oil model for petroleum reservoir simulation. SIAM Journal on Applied Mathematics, 49(3), 749-783.

Ukpaka C.P. and C. Ukpaka (2016). Model prediction for constant area, variable pressure Drop in orifice plate characteristics in flow system. Chemistry International, 2(2,) 80-88.

Zhang, H., Liang, Y., Ma, J., Qian, C., \& Yan, X. (2017). An MILP method for optimal offshore oilfield gathering system. Ocean Engineering, 141, 25-34.

\section{APPENDIX}

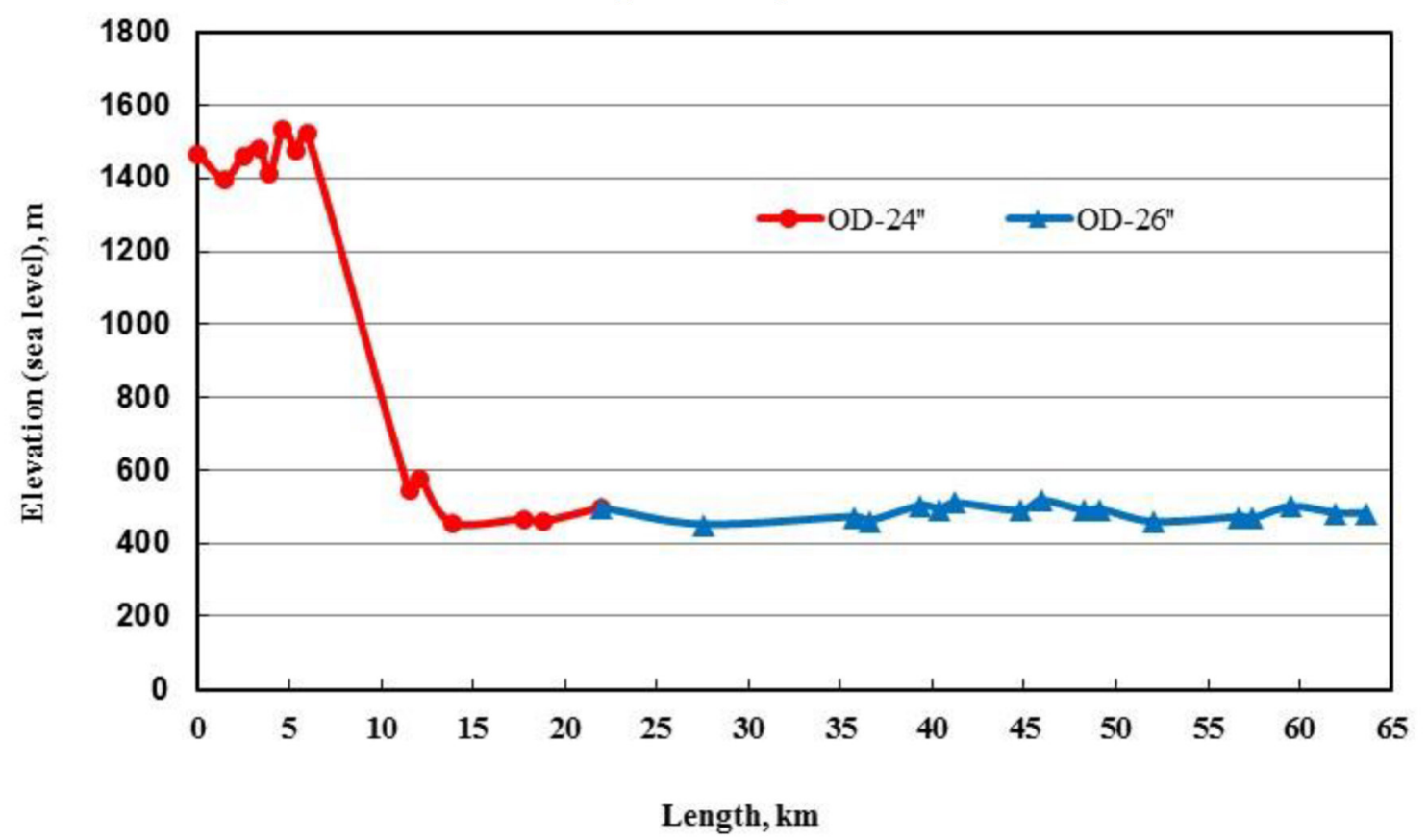

Figure A.1: Pipeline Elevation Profile sourced from Mansoori et al 